\title{
Capacity reservation under supply uncertainty
}

\author{
Doğan A. Serel* \\ Faculty of Business Administration, Bilkent University, Bilkent, Ankara 06533, Turkey
}

Available online 10 October 2005

\begin{abstract}
Shortages of input materials and components used in the production process often adversely influence sales of manufacturing firms. Manufacturers can guarantee delivery of the inputs by initiating capacity reservation arrangements with their suppliers. We study a multi-period capacity reservation contract between a manufacturer and a long-term supplier when there is uncertainty about the quantity of an input item available in the spot market. The contract requires the manufacturer to pay a fixed amount to the supplier at each period. In return, the supplier guarantees availability of the input up to a predetermined level of volume. The manufacturer can also meet some of input needs from a spot market, which may exist in the form of a B2B electronic exchange. Optimal inventory policy for the manufacturer in this dual supplier environment is derived analytically. Numerical examples are used to explore the strategies of the manufacturer and the supplier in certain and uncertain supply environments. We find that uncertain input markets lead to an increase in the share of inputs purchased in advance via long-term contracts. Capacity reservation contracts are shown to increase capacity utilization of the supplier compared to the traditional unit-price based supply contracts.

(C) 2005 Elsevier Ltd. All rights reserved.
\end{abstract}

\section{Introduction}

Manufacturers choose their suppliers based on a variety of factors including cost and reliability of deliveries, potential level of collaboration in developing new products, and the range of needs that can be satisfied by the supplier. The increased ability to interact with a large number of suppliers over the Internet has considerably expanded the options available for procuring manufacturing inputs. An important strategic decision is whether to procure inputs via a long-term supply contract with a selected supplier, or through existing spot markets without any long-term commitment. Although long-term supply

* Tel: +903122902415; fax: +903122664958.

E-mail address: serel@bilkent.edu.tr. 
contracts with preferred suppliers have been considered a critical element of the just-in-time production and total quality management philosophies, it may be possible to utilize the existing spot markets for some immediate purchases and thus reduce the level of commitment to a single source in material inflows.

Manufacturers are occasionally confronted with shortages of components and raw materials; they need to be obtained from outside vendors. These shortages may be due to the delays in suppliers' response to changing market conditions. When there is uncertainty in the supply of a particular input, a manufacturer may be more willing to reserve future supplier capacity in advance and thus guarantee the availability of the input. Disruptions in supply inflows may adversely affect profitability through an increase in lost sales of the finished good. To counteract this problem, buyers can be expected to shift to long-term contracts and closer supplier relationships as the supply variability increases, as observed in the case of DuPont's backward vertical integration with an oil supplier firm, Conoco [1].

In this paper, we study the capacity reservation decisions of manufacturers in uncertain supply markets. We extend the capacity reservation model (developed in [2]) which is built upon the assumption of certainty in supply availability. A capacity reservation agreement between a manufacturer and a supplier involves the determination of two contract terms: capacity price and quantity. The manufacturers reserve supply capacity in advance, mainly to reduce purchase cost and delivery risk; suppliers enter these agreements because of expected increases in utilization of their installed productive capacity.

We consider a manufacturer (buyer) who needs to purchase an input to be used in the manufacturing process which turns out a finished good with a stochastic demand in the market. The buyer has to periodically replenish their inventory of the purchased item; this task involves a consideration of the tradeoffs between the holding and shortage costs associated with overstocking and understocking, respectively. The specific input can be acquired either from the spot market, or through a long-term capacity reservation contract with a preferred supplier. This contract stipulates that in each period, the supplier prepares to supply the buyer with up to a predetermined quantity of the input item. The buyer, depending on his current inventory level, may not use the entire reserved capacity every period. The unit capacity price is considered to be constant. This type of advance capacity purchase is observed in different industries such as electric power, and semiconductor manufacturing [3]. Combined use of advance and spot buying also occurs in the transportation industry [4,5]. In our model, the buyer tries to maximize his expected profit by deciding the optimal inventory control policy and the optimal amount reserved from the long-term supplier; the long-term supplier, on the other hand, needs to determine the optimal unit capacity price to maximize her expected profit. Thus, the problem is studied from the perspective of both the buyer and the supplier.

The degree of uncertainty in the spot market supply is one of the factors that should be taken into account in negotiating the capacity reservation contract. Based on a multi-period stochastic inventory model, the following research questions are addressed in this paper: (1) How do reserved capacity quantity and price differ in certain, and uncertain, supply environments? (2) Given an uncertain supply environment, how do changes in supply availability influence the terms of the contract? (3) How much can capacity reservation improve a supplier's capacity utilization and profits? (4) Which of "supply uncertainty" and "finished good demand uncertainty" is likely to be the more dominant factor driving the manufacturer's capacity reservation decision?

The decisions of both buyer and supplier are influenced by whether there is a reliable flow of supply in the spot market; this factor affects the resulting capacity reservation price and quantity. When the spot market is a reliable source of procurement, the long-term supplier is pressured to set a price below the spot market price. However, if the amount that can be obtained from the spot market is uncertain, the price 
pressure on the long-term supplier is reduced, and the contract negotiations occur under less favorable conditions for the buyer. Our numerical study indicates that, compared to the case of certainty in spot supply, in the uncertain spot supply case the long-term supplier can increase profits by selling a higher amount of capacity in advance but, to some extent unexpectedly, at a lower price.

As expected intuitively, increases in the spot supply availability given the uncertain supply environment reduce the unit price of the capacity. Since the buyer requires an increase in his expected profit as the average amount available in the spot market increases, the long-term supplier can respond to this requirement by decreasing the capacity price and/or by providing the buyer with a higher volume of reserved capacity, thus reducing the lost sales of the finished good. Our numerical experiment yields results supporting these arguments.

Compared to the traditional constant unit-price procurement contracts, our computational examples show that up to $10 \%$ increases in the supplier's capacity utilization rates are possible by switching to the capacity reservation contract.

When the spot market supply is reliable, increasing uncertainty in demand for the finished good increases the spot market share in the buyer's procurement plan [2]. In this study, we find that when the spot market is a risky alternative for the buyer, the long-term supplier can effectively substitute for the spot market regardless of the existing level of uncertainty in demand for the finished good. This implies that variability of finished good demand plays a less influential role in the manufacturer's capacity reservation decision than variability in the supply of inputs.

Consistent with the observed cases in practice, we find that long-term relationships are more likely to thrive when supply markets involve uncertainty. Using numerical examples, we investigate the impact of changes in various model parameters on optimal capacity reservation and price decisions made by the parties.

\section{Literature review}

This paper is related in varying degrees to several research streams in the operations management literature. A topic of recent interest is the study of the supply chain procurement strategies combining spot market purchases with purchases made in advance from a specific long-term supplier. Bonser and $\mathrm{Wu}$ [6] study the fuel procurement problem for electric utilities in which the buyer can use a mix of long-term and spot purchases. In our analytical model in this paper, there is a long-term supplier who has to choose his supply price given the competition caused by the spot market alternative for the buyer. This problem was first defined and studied in the inventory literature in Serel et al. [2]. They investigated the relative values of short and long-term supply contracts for a buyer using classical inventory models, and found that the incorporation of spot market purchases into the buyer's procurement strategy may substantially reduce the capacity that must be reserved from the long-term supplier compared to a singlesourcing arrangement. $\mathrm{Wu}$, Kleindorfer, and Zhang [7] consider uncertainty in spot market prices, and analyze the contracts for non-storable goods involving options executable at a predetermined price. Using a similar single-period model, Spinler and Huchzermeier [8] show that, mainly due to the decrease in the supplier's production costs when an options contract is used, the combination of an options contract and a spot market is Pareto improving with respect to the other alternative market structures. Seifert et al. [9] also analyzed a single-period problem from the buyer's standpoint with changing levels of buyer's risk preferences. Kleindorfer and $\mathrm{Wu}$ [3] linked this literature to evolving B2B exchanges on the Internet. 
A relatively older research stream related to the current paper concerns the optimal periodic review inventory policies when there is uncertainty in supply availability in the future. Ciarallo et al. [10] study optimal inventory decisions when the amount of production capacity in each period is a random variable. Extensions of this approach have been studied in [11,12]. Wang and Gerchak [13] derive the optimal inventory policy when both capacity and yield of a production process vary simultaneously. Hwang and Singh [14] investigate a single-period, multi-stage serial production system with random production capacity in each stage. Another research stream has explored the case in which only one of two events occurs each period: (1) with a known probability, the quantity ordered by the buyer is fully received, or (2) the order is not met by the supplier, i.e., no delivery occurs. Parlar et al. [15] develop a model in which the probability of the supplier being available in a period depends on the availability status of the supplier in the previous period. Ozekici and Parlar [16] extend this model to the case of multiple supply environments with a different probability for supplier availability in each environment. Tan [17] investigates a capacitated manufacturer-subcontractor system in which the subcontractor is unavailable to the manufacturer for a random duration. Some other papers in this area are reviewed in Mohebbi [18]. Our work extends these single-supplier models in the literature to a dual-supplier environment in which the buyer contracts with a separate long-term supplier to reduce the delivery risk associated with the short-term supplier. Although our main structural results also hold for the case in which an unreliable supplier delivers either the full order amount or nothing in each period, in our presentation we base our model on the assumption of random variation in the maximum supply quantity available in each period. The earlier studies on the single-supplier random capacity problem are a building block for the capacity reservation problem explored in the current paper; the structural properties of the single-supplier model are suitably extended to the dual-supplier model that we consider. The periodic review inventory control systems with restricted but certain supply have also been investigated in the literature [19].

Wholesale price discounts offered by suppliers in order to encourage advance purchase commitments and capacity reservations by buyers have been explored in a number of papers in recent years. The papers in this area are also related to the current article since they deal with the issue of reservation of supplier capacity by a buyer as a protective measure against uncertain future demand. Various types of supply contracts involving advance capacity purchases have been investigated, generally based on a singleperiod framework. Erkoc and $\mathrm{Wu}$ [20] model the negotiations between a manufacturer and a supplier when the supplier has to make a costly investment in additional production capacity. Jin and $\mathrm{Wu}$ [21] analyze capacity reservation contracts between a single supplier and multiple buyers with reservation fees deductible from the purchase price paid in delivery. Deng and Yano [22] study the contracts between a component supplier and a manufacturer involving a fixed wholesale price for advance purchases, and a spot price determined and charged for purchases after the demand is realized. Cachon [23] studies how allocation of the cost of unsold inventory among a supplier and a retailer influences the overall supply chain efficiency. Again, based on the assumption of a single selling season for the finished good, Ferguson [24] explores the timing decisions for sale of components by a supplier to a manufacturer assuming that the wholesale price is set by the more powerful party in the relationship. In a similar setting, the impact of uncertainty reduction in demand forecast by new information arriving during the supplier's lead time is analyzed in Ferguson et al. [25]. Tsay [26] studies the use of a quantity flexibility contract to coordinate a manufacturer-retailer chain under demand uncertainty. Burnetas and Ritchken [27] look into the impact of option contracts on the wholesale and retail prices under price-dependent demand in a manufacturer-retailer chain. Other papers on the use of options in supply chains include $[28,29]$. 


\section{Model}

The setting in the current paper is similar in spirit to [2]. We assume that items ordered are immediately delivered to the buyer, and transformed into finished goods in a time negligible with respect to the period length. Without loss of generality, we assume one unit of input is required for one unit of finished product. The random demand for the finished good is independently and identically distributed in each period with mean $\mu$. If demand exceeds the stock of finished goods on hand, excess demand is lost. Lost sales are assumed rather than backordering of demand because the possibility of lost sales creates more motivation for reserving capacity in advance. The unit purchase cost of the input in the spot market, $c_{2}$, and the unit cost of all other inputs combined, $c_{0}$ are given. $p$ denotes the actual selling price of the finished good in the market minus $c_{0}$; thus, the difference between $p$ and the purchase cost of the specific input under study represents the contribution of that input to the company's gross profit. As usual in the inventory literature, we assume $p>c_{2}$. The spot market price $c_{2}$ is considered to be the price charged by a homogeneous group of short-term suppliers under market equilibrium.

As a condition of the capacity reservation contract, the buyer will pay the long-term supplier a fixed monetary amount $c R$ in each period, regardless of the actual amount ordered in that period. $R$ is the reserved capacity level chosen by the buyer. The unit capacity price $c$ is determined as a result of negotiations between the buyer and the supplier, and the spot market price $c_{2}$ is an exogenous parameter influencing this negotiation process. The assumption that the capacity sold by the long-term supplier is linearly priced implies that the supplier is not able to induce the buyer to choose his reservation quantity in accordance with the objective of maximizing the combined profit of the buyer and the supplier. Various alternatives such as quantity discounts, buy-back contracts, and revenue-sharing agreements have been proposed in the literature to coordinate the decisions of the buyer and the supplier in a single-period, newsvendor framework, see, e.g., [30]. We recognize that not only is coordination difficult to achieve but it also involves the issue of how to distribute the total channel profit among the parties; therefore, we focus on the common case of linear supply prices, and consider the Stackelberg equilibrium with the supplier being the leader.

One of the major purposes of the current paper is to investigate the impact that the uncertainty about availability of inputs in the spot market has on the buyer's relationship with the long-term supplier. In [2], an infinite amount of inputs in the spot market is assumed to be available in each period, and the buyer is motivated to reserve capacity because of the lower-than-market cost offered by the long-term supplier. However, when the availability of inputs in the spot market is not guaranteed, this situation generates an additional motivation for the buyer to reserve capacity. In fact, the optimal unit capacity price charged by the supplier is no longer restricted to less than the spot market price since the buyer may find it beneficial to reserve capacity at a higher-than-market cost rather than taking the risk of delivery problems associated with the spot market source. We assume that the random amount of supply available from the spot market is independently and identically distributed in each period, with mean $\gamma$. We also assume that the demand for the final product and the amount of supply in the spot market are independent of each other. This assumption is not so restrictive since in certain industries, changes in the supply of inputs may be unrelated to changes in demand for the finished good [31]. The relaxation of the independence assumption, besides requiring additional parameter estimates and reducing analytical tractability, makes the numerical calculations more time consuming and cumbersome.

When the available supply in the spot market is uncertain, it can be argued that the spot price should also depend on the quantity available, perhaps in a negative direction. If a functional relationship between 
the spot quantity and price is assumed, it is possible to solve the problem based on the control policy prescribed for the constant spot price case, albeit at a higher computational effort. However, the optimal control policy under the quantity-dependent spot price assumption is harder to derive analytically, and the policy optimal for the constant spot price case is not guaranteed to be optimal in this case. We note that even if the true optimal policy is taken into account, the optimal decisions of the parties with this refinement are not likely to be significantly different from those obtained from the current model. This is because the parties make their decisions not for a single period but over a large number of repetitive periods so that the impact of the random spot price will average out. Note also that, without additional restrictions on the spot supply probability distribution, a simple form of optimal inventory control policy as in the constant spot price case may not exist even for the single-period problem with a relatively simple assumption of a linear relationship between supply quantity and price. The constant spot price used in our model can be thought of as the long-run average spot price perceived by the buyer and the preferred supplier, based on their forecast of the probability distribution of the amount of input available from the group of short-term suppliers. To demonstrate the plausibility of the constant spot price assumption, in Section 6, we present numerical results for the same sample problem based on both the constant spot price and the quantity-dependent spot price cases.

For the finished good, the inventory-holding cost is $h$, and the shortage penalty cost is $\pi$ per unit per period, based on the period-ending inventory. The buyer's problem is to maximize his expected profit per period over an infinite horizon, given the supply costs associated with the long-term supplier and the spot market source. The supplier's problem is to identify the best unit capacity price that maximizes her expected profit per period. The long-term supplier is assumed to have unit production $\operatorname{cost} c_{\mathrm{s}}$ for the input item.

The capacity reservation agreement considered in this paper offers a mutually beneficial mechanism for a buyer and a supplier willing to strengthen their relationship. The buyer may receive cost advantages and reduce future delivery risk in an uncertain supply market. The supplier is given a major portion of the buyer's orders without having to commit to excessive capacity levels, and by being a preferred supplier, obtains a chance to collaborate with the buyer in some other business activities. Further benefits resulting from this agreement are discussed in the conclusion section. A summary of the notation is given below.

\section{Notation}

$R \quad$ amount of reserved capacity per period

$c \quad$ unit price of capacity or supply price per unit charged by the long-term supplier

$c_{2} \quad$ supply price per unit in the spot market

$p \quad$ unit selling price of the finished good charged by the buyer

$h \quad$ holding cost per unit per period

$\pi \quad$ shortage penalty cost per unit per period

$f($.$) \quad probability density function (pdf) for demand$

$F($.) cumulative probability distribution function (cdf) for demand

$F_{\mathrm{c}}($.) complementary cumulative probability distribution function for demand

$Y \quad$ random demand per period

$\mu \quad$ mean demand per period

$g($.) probability density function for the amount available in the spot market

$G($.) cumulative distribution function for the amount available in the spot market 


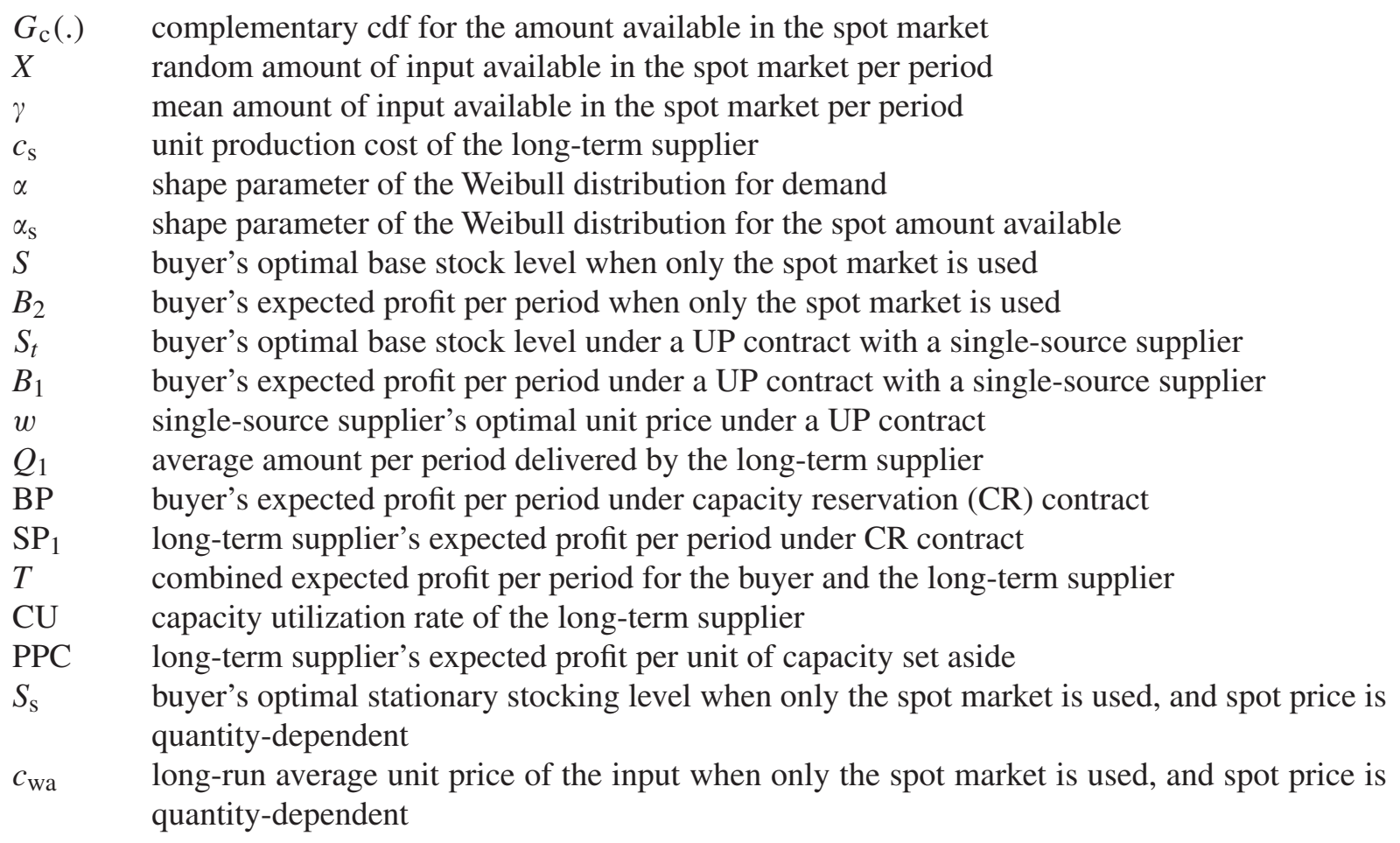

\section{Analysis of the capacity reservation contract}

\subsection{Buyer's problem}

The buyer's problem can be solved in two steps. First, the capacity reservation fee $c R$ is considered as a sunk cost, and the optimal inventory control policy for a given $R$ is determined. In the second step, the $\operatorname{cost} c R$ is also included in the expected profit function, and the optimal value of the capacity reservation amount $R$ is identified. In this section, we first analytically obtain the form of the optimal inventory control policy. Subsequently, we discuss determining the optimal values of the policy parameters based on a discrete Markov chain.

Before stating the buyer's problem formally, it may be useful to clarify the difference between the planned and realized period-starting inventory levels in our model. Each period, the buyer has to decide what portion of the reserved capacity to use, and how many units to order from the spot market. Let $Z_{n}$ be the planned starting inventory level (after ordering) in period $n$, and $Z_{n r}$ be the actual starting inventory level after ordering in period $n$. Further, let the random variable $X_{n}$ be the maximum amount available for the buyer in the spot market in period $n$. Because of the uncertainty associated with $X_{n}, Z_{n r}$ can be less than $Z_{n}$ in some periods. Let $I_{n}$ be the inventory level before ordering in period $n$. Because the buyer uses first the long-term supplier, given $x_{n}$ units in the spot market, the realized inventory level is related 
to the planned inventory level as follows:

$$
\begin{aligned}
& Z_{n r}=Z_{n} \quad \text { if } Z_{n} \leqslant x_{n}+I_{n}+R, \\
& Z_{n r}=x_{n}+I_{n}+R \quad \text { if } Z_{n}>x_{n}+I_{n}+R .
\end{aligned}
$$

After the orders from both sources are received, the buyer uses the amount of input available $\left(Z_{n r}\right)$ in the manufacture of the finished good. Then, demand for the finished good is observed. Let $y_{n}$ be the realized demand for the finished good in period $n$. Thus, the selling revenue minus inventory holding and shortage costs in period $n, L\left(Z_{n r}\right)$ is

$$
p \min \left(Z_{n r}, y_{n}\right)-h\left(Z_{n r}-y_{n}\right)^{+}-\pi\left(y_{n}-Z_{n r}\right)^{+} .
$$

The optimal inventory control policy for the buyer will be derived following standard inductive procedure. The steps are along the lines of Ciarallo et al. [10], where a single-supplier problem is solved. After identifying the form of the optimal inventory control policy in the last period of the planning horizon, this policy is assumed to hold for the $N-1$-period problem, and then it is shown to hold for the $N$-period problem. Finally, we consider the extension of the finite-horizon results to the infinite-horizon case.

We first solve the single-period problem. To find the optimal stocking level, we ignore the capacity reservation fee $c R$, and consider the remaining costs for optimizing. Let $G($.) denote the cdf of the amount available in the spot market. Given the inventory on hand $I$, the buyer needs to determine the optimal planned inventory level, $Z$. Note that the optimal inventory level is determined prior to observing the amount available in the spot market. The buyer's problem can be stated as (cf. [10]):

$$
\begin{aligned}
& P(I)=\text { Maximize }\{S(I, Z): Z \in \zeta(I)\}, \\
& \begin{aligned}
S(I, Z)= & (1-G(Z-I-R))\left[E L(Z)-c_{2}(Z-I-R)\right] \\
& +p \int_{0}^{Z-I-R} \int_{0}^{x+R+I} y f(y) g(x) \mathrm{d} y \mathrm{~d} x \\
& +p \int_{0}^{Z-I-R} \int_{x+R+I}^{\infty}(x+R+I) f(y) g(x) \mathrm{d} y \mathrm{~d} x \\
& -h \int_{0}^{Z-I-R} \int_{0}^{x+R+I}(x+R+I-y) f(y) g(x) \mathrm{d} y \mathrm{~d} x \\
& -\pi \int_{0}^{Z-I-R} \int_{x+R+I}^{\infty}(y-x-R-I) f(y) g(x) \mathrm{d} y \mathrm{~d} x \\
& -c_{2} \int_{0}^{Z-I-R} x g(x) \mathrm{d} x \quad \text { if } Z \geqslant I+R,
\end{aligned}
\end{aligned}
$$

$$
S(I, Z)=E L(Z) \quad \text { if } Z<I+R,
$$

where $g(x)$ is the pdf of the spot market supply distribution, $f(y)$ is the pdf of the demand distribution, and $\zeta(I)$ is the set of admissible values for planned inventory after ordering, i.e., $Z \geqslant I$. In the case $Z<I+R$, the buyer does not use the spot market so his expected profit is not influenced by the probability distribution of the spot market supply. For the case $Z \geqslant I+R$, the first term on the right-hand side (RHS) of (1) is the buyer's expected profit conditional on the spot supply being sufficient to achieve the planned stocking level $Z$, multiplied by the probability that the spot supply will be sufficient. The remaining five terms 


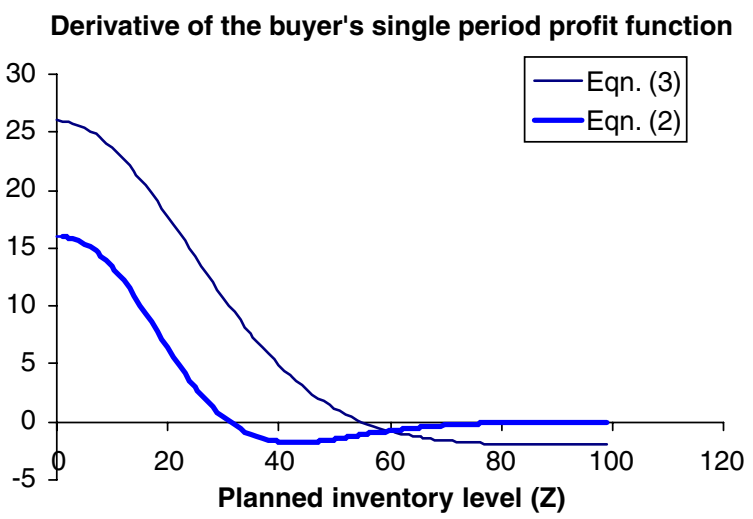

Fig. 1. Plot of $S^{\prime}(I, Z)$ given by Eqs. (2) and (3).

constitute the contribution to the buyer's expected profit when the spot supply available is less than the planned order amount from the spot market. Without loss of generality, we assume the salvage value associated with leftover items at the end of the period to be zero. The following proposition states the general form of the optimal policy.

Proposition 1. The optimal inventory ordering policy for the buyer is defined by two numbers $Z_{1}$ and $Z_{2}$ in the single-period problem.

Proof. Some algebra indicates that the first partial derivative of $S(I, Z)$ given by (1) with respect to $Z$, $S^{\prime}(I, Z)$, is

$$
\begin{aligned}
& S^{\prime}(I, Z)=(1-G(Z-I-R))\left[(p+\pi)(1-F(Z))-h F(Z)-c_{2}\right] \text { if } Z \geqslant I+R, \\
& S^{\prime}(I, Z)=(p+\pi)(1-F(Z))-h F(Z) \quad \text { if } Z<I+R .
\end{aligned}
$$

As a visual aid for the following analysis, the values of $S^{\prime}(I, Z)$ given by (2) and (3) are plotted against $Z$ in Fig. $1(R=5, I=0)$ for a specific example. The curve on the left in Fig. 1 (plot of (2)) intersects with the horizontal axis at $Z=Z_{1} \approx 31$, and the other curve intersects with the $x$-axis at $Z=Z_{2}=55$. Define $D(Z)=\partial E L(Z) / \partial Z=(p+\pi)(1-F(Z))-h F(Z)$. It is straightforward to show that

$$
D^{\prime}(Z)=-(p+\pi+h) f(Z) \leqslant 0,
$$

and $E L(Z)$ is concave in $Z$. Let $Z_{1}$ be such that $D\left(Z_{1}\right)-c_{2}=0$ and $Z_{2}$ be such that $D\left(Z_{2}\right)=0$. That is,

$$
\begin{aligned}
& Z_{1}=\max \left\{Z:(p+\pi)(1-F(Z))-h F(Z) \geqslant c_{2}\right\}, \\
& Z_{2}=\max \{Z:(p+\pi)(1-F(Z))-h F(Z) \geqslant 0\} .
\end{aligned}
$$

Since $D\left(Z_{1}\right)=c_{2}>0$ and $D^{\prime}(Z) \leqslant 0$, it follows that $Z_{1}<Z_{2}$. Observe that, for $Z \geqslant I+R, S^{\prime}(I, Z) \leqslant 0$ when $Z \geqslant Z_{1}$. The second partial derivative of $S(I, Z)$ with respect to $Z$ is

$$
S^{\prime \prime}(I, Z)= \begin{cases}-g(Z-I-R)\left\{D(Z)-c_{2}\right\}+(1-G(Z-I-R)) D^{\prime}(Z) & \text { if } Z \geqslant I+R \\ D^{\prime}(Z) & \text { if } Z<I+R .\end{cases}
$$




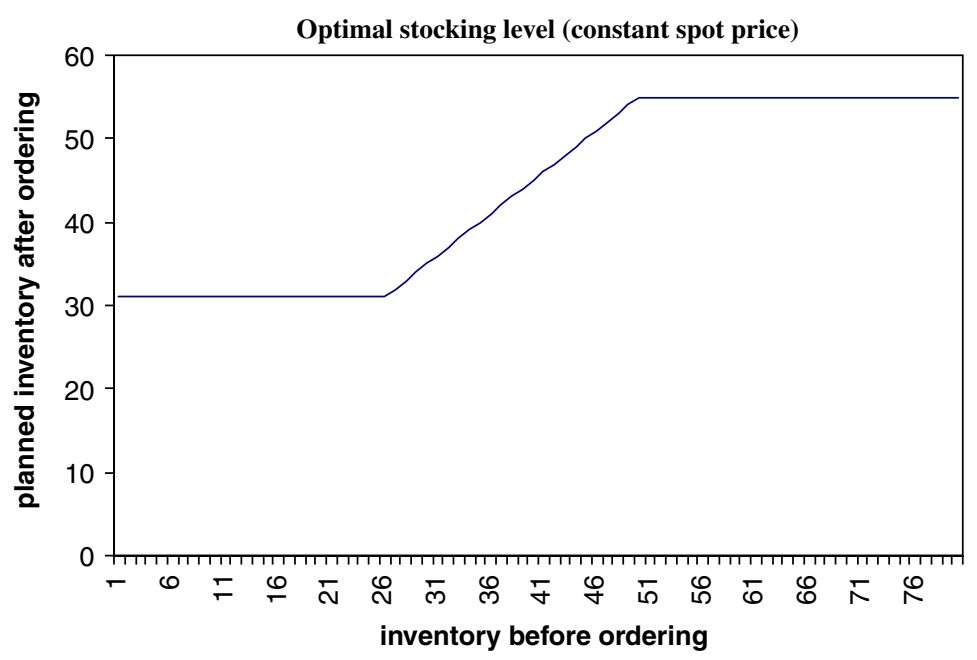

Fig. 2. Buyer's optimal inventory decision in the single-period problem under constant spot price.

It can be seen from the expression for $S^{\prime \prime}(I, Z)$ that for $Z \geqslant I+R, S^{\prime \prime}(I, Z) \leqslant 0$ when $Z \leqslant Z_{1}$. Since we also know that $S^{\prime}(I, Z) \leqslant 0$ when $Z \geqslant I+R$ and $Z \geqslant Z_{1}$, it follows that the function $S(I, Z)$ is quasi-concave in $Z$ for $Z \geqslant I+R$. Since $D^{\prime}(Z) \leqslant 0, S(I, Z)$ is concave in $Z$ for $Z<I+R$. Combining these results for $S(I, Z)$ in the two regions $Z \geqslant I+R$ and $Z<I+R$, we can state that the optimal planned inventory level, $Z^{*}$, is as follows:

$$
Z^{*}= \begin{cases}Z_{1} & \text { if } I+R \leqslant Z_{1}<Z_{2} \\ I+R & \text { if } Z_{1}<I+R \leqslant Z_{2} \\ I+\left(Z_{2}-I\right)^{+} & \text {if } Z_{1}<Z_{2}<I+R\end{cases}
$$

Proposition 1 indicates that the optimal planned inventory level is not affected by uncertainty in spot market supply. The numbers $Z_{1}$ and $Z_{2}$ are the same as those in the infinite spot market supply case. This relationship does not carry over to the multi-period problem in which inventory can be used to hedge against possible future supply disruptions. The form of an optimal policy specified by Proposition 1 (for the same numerical example used in Fig. 1) is shown in Fig. 2. To display the values of $Z_{1}$ and $Z_{2}$ clearly on the graph, in this example we assumed zero disposal cost for the starting inventory; hence, we allowed the possibility that $Z$ can be less than $I$.

Consider now the multi-period problem under the maximum total discounted profit criterion with periods numbered backward, and the single-period discount factor denoted by $\rho$. Assume that salvage value function $B_{0}(I)=0$. We also assume that the initial inventory on hand at the beginning of the first period in the planning horizon is small, or alternatively, that the cost of reducing the initial inventory on hand to a level below the optimal planned inventory level is considered a sunk cost. We can write the recurrence relation in the dynamic program as

$$
\begin{aligned}
& B_{n}\left(I_{n}\right)=\operatorname{Maximize}\left\{T_{n}\left(I_{n}, Z_{n}\right): Z_{n} \in \zeta\left(I_{n}\right)\right\}, \\
& T_{n}\left(I_{n}, Z_{n}\right)=S\left(I_{n}, Z_{n}\right)+\rho \int_{0}^{\infty} B_{n-1}\left(\max \left(0, Z_{n}-y\right)\right) f(y) \text { dy } \quad \text { if } Z_{n}<I_{n}+R,
\end{aligned}
$$




$$
\begin{aligned}
T_{n}\left(I_{n}, Z_{n}\right)= & S\left(I_{n}, Z_{n}\right)+\rho \int_{0}^{\infty} \int_{0}^{Z_{n}-I_{n}-R} B_{n-1}\left(\max \left(0, I_{n}+R+x-y\right)\right) g(x) f(y) \mathrm{d} x \mathrm{~d} y \\
& +\rho\left(1-G\left(Z_{n}-I_{n}-R\right)\right) \int_{0}^{\infty} B_{n-1}\left(\max \left(0, Z_{n}-y\right)\right) f(y) \mathrm{d} y \quad \text { if } Z_{n} \geqslant I_{n}+R .
\end{aligned}
$$

The second and third terms on the RHS of (5) are the discounted total expected profit in the next and subsequent periods if the spot supply in the current period is insufficient and sufficient, respectively. Taking the derivative of (4) and using (3), for $Z_{n}<I_{n}+R$ we obtain

$$
\begin{aligned}
\partial T_{n}\left(I_{n}, Z_{n}\right) / \partial Z_{n}= & (p+\pi) F_{\mathrm{c}}\left(Z_{n}\right)-h F\left(Z_{n}\right) \\
& +\rho \int_{0}^{\infty} B_{n-1}^{\prime}\left(\max \left(0, Z_{n}-y\right)\right) f(y) \mathrm{d} y \quad \text { if } Z_{n}<I_{n}+R .
\end{aligned}
$$

Similarly, for $Z_{n} \geqslant I_{n}+R$,

$$
\begin{aligned}
\partial T_{n}\left(I_{n}, Z_{n}\right) / \partial Z_{n}= & \partial S\left(I_{n}, Z_{n}\right) / \partial Z_{n}+\rho\left(1-G\left(Z_{n}-I_{n}-R\right)\right) \\
& \times \int_{0}^{\infty} B_{n-1}^{\prime}\left(\max \left(0, Z_{n}-y\right)\right) f(y) \mathrm{d} y .
\end{aligned}
$$

Using (2) and (7), we have

$$
\begin{aligned}
\partial T_{n}\left(I_{n}, Z_{n}\right) / \partial Z_{n}= & G_{\mathrm{c}}\left(Z_{n}-I_{n}-R\right)\left\{(p+\pi) F_{\mathrm{c}}\left(Z_{n}\right)-h F\left(Z_{n}\right)-c_{2}\right. \\
& \left.+\rho \int_{0}^{\infty} B_{n-1}^{\prime}\left(\max \left(0, Z_{n}-y\right)\right) f(y) \mathrm{d} y\right\} \quad \text { if } Z_{n} \geqslant I_{n}+R .
\end{aligned}
$$

$G_{\mathrm{c}}($.$) and F_{\mathrm{c}}($.$) represent the complementary cdf's of spot market supply and demand, respectively. Based$ on (6) and (8), the second partial derivatives are

$$
\begin{aligned}
\partial^{2} T_{n}\left(I_{n}, Z_{n}\right) / \partial Z_{n}^{2} & \\
=-f\left(Z_{n}\right)(p+\pi & +h)+\rho \int_{0}^{\infty} B_{n-1}^{\prime \prime}\left(\max \left(0, Z_{n}-y\right)\right) f(y) \mathrm{d} y \quad \text { if } Z_{n}<I_{n}+R \\
\partial^{2} T_{n}\left(I_{n}, Z_{n}\right) / \partial Z_{n}^{2}= & G_{\mathrm{c}}\left(Z_{n}-I_{n}-R\right)\left\{-f\left(Z_{n}\right)(p+\pi+h)\right. \\
& \left.+\rho \int_{0}^{\infty} B_{n-1}^{\prime \prime}\left(\max \left(0, Z_{n}-y\right)\right) f(y) \mathrm{d} y\right\} \\
& -g\left(Z_{n}-I_{n}-R\right)\left\{(p+\pi) F_{\mathrm{c}}\left(Z_{n}\right)-c_{2}-h F\left(Z_{n}\right)\right. \\
& \left.+\rho \int_{0}^{\infty} B_{n-1}^{\prime}\left(\max \left(0, Z_{n}-y\right)\right) f(y) \mathrm{d} y\right\} \quad \text { if } Z_{n} \geqslant I_{n}+R .
\end{aligned}
$$

We now show that $B_{n}\left(I_{n}\right)$ is concave in $I_{n}$.

Proposition 2. The function $B_{n}\left(I_{n}\right)$ is concave in the starting inventory, $I_{n}$.

Proof. See Appendix A. 
Proposition 3 implies that, similar to the single-period case, the first-order condition can be used to determine the optimal $Z_{n}$ in the multi-period problem.

Proposition 3. The function $T_{n}\left(I_{n}, Z_{n}\right)$ is quasi-concave in $Z_{n}$ for $Z_{n} \geqslant I_{n}+R$, and concave in $Z_{n}$ for $Z_{n}<I_{n}+R$.

Proof. See Appendix A.

Proposition 3 leads to the next proposition which states that the optimal inventory control policy for the buyer is described by two numbers $\mathrm{SL}_{n}$ and $\mathrm{SU}_{n}$ for each period; although the numbers may change depending on the probability distribution of the supply in the spot market, this structure is similar to the optimal policy in the infinite spot market supply case.

Proposition 4. In the finite horizon problem under the total discounted profit criterion, an inventory control policy with two critical numbers in each period $\left(\mathrm{SL}_{n}, \mathrm{SU}_{n}\right)$ maximizes the buyer's expected profit.

Proof. See Appendix A.

We state the stationary infinite horizon version of Proposition 4 in Proposition 5.

Proposition 5. In the infinite horizon problem under the total discounted profit criterion, an inventory control policy with two stationary critical numbers (SL, SU) maximizes the buyer's expected profit.

Proof. See Appendix A.

Proposition 5 states that as $n \rightarrow \infty$, the two control numbers $\mathrm{SL}_{n}$ and $\mathrm{SU}_{n}$ become period-independent and converge to constants SL and SU. Although the buyer tries to start each period with at least SL units on hand, due to the possibility of limited supply in the spot market, the starting inventory level in some periods could be less than SL. This structure of the optimal policy is not very surprising. The buyer's problem has a unique solution when we treat each source separately as a single source. The problem in which the buyer procures only from the long-term supplier using a capacity reservation contract is concave with respect to the reserved capacity. The buyer's problem when the amount of supply available from a single source is random has been shown to be quasi-concave by Ciarallo et al. [10], implying the optimality of a base stock control policy. Similar to [2], in the rest of the paper, we assume that the buyer's optimal policy under the average profit criterion has the same form as that under the total discounted profit criterion derived above.

The inventory levels in each period, $I_{n}$, constitute a Markov chain for which the transition probabilities can be calculated. The one-step transition probabilities $P\left(I_{n-1}=j \mid I_{n}=i\right)=p_{i j}$ are

$$
p_{i j}=\left[\begin{array}{ll}
P\left(Y_{n}=\mathrm{SU}-j\right) & \text { if } \mathrm{SU}-R \leqslant i \leqslant \mathrm{SU}, \\
P\left(Y_{n}=i+R-j\right) & \text { if } \mathrm{SL}-R \leqslant i<\mathrm{SU}-R, \\
P\left(Y_{n}=\mathrm{SL}-j\right) P\left(X_{n}>\mathrm{SL}-R-i\right) & \\
\quad+\sum_{k=0}^{\mathrm{SL}-R-i} P\left(X_{n}=k\right) P\left(Y_{n}=i+R+k-j\right) & \text { if } i<\mathrm{SL}-R .
\end{array}\right.
$$


Note that since we assume lost sales, after we compute $p_{i j}$ according to (11), we revise the value of $p_{i 0}$. Using these transition probabilities, we can determine the steady-state probabilities of inventory levels and compute the expected profits associated with different choices of $R, \mathrm{SL}$ and SU. The optimal values of SL and SU in the buyer's problem depend on $R$, but not directly on $c$. We have used the Hooke and Jeeves search algorithm [32] to find the optimal values of these parameters. In the implementation of this algorithm, the buyer's full expected profit function includes the capacity reservation fee $c R$, i.e., $-c R$ is added to the single-period profit function $S(I, Z)$ in Eq. (1).

\subsection{Supplier's problem}

The long-term supplier quotes her unit capacity price, $c$, based on expected sales to the buyer. For a given $c$, the supplier's expected profit per period, $\mathrm{SP}_{1}$, is

$$
\mathrm{SP}_{1}=c R-c_{\mathrm{S}} Q_{1}(R) .
$$

where $Q_{1}(R)$ is the average amount shipped to the buyer each period. In order to determine the optimal $c$, the supplier needs to know the $R$ value chosen by the buyer for every possible $c$ value. Since analytical treatment of the supplier's profit function is difficult, the optimal solution will be found by conducting a brute-force search over the whole solution space, which is discretized in small increments of $c$.

\subsection{Price of capacity in equilibrium}

The price which maximizes $\mathrm{SP}_{1}$ given in (12) may not be the equilibrium capacity price in our model. When the supplier maximizes her expected profit, there is no guarantee that the buyer will be better off compared to the case in which there is no long-term contract. The buyer will enter a relationship with the long-term supplier if the relationship increases his expected profit. Let $B_{2}$ be the buyer's expected profit per period when only the spot market source is available. Then it can be argued that an appropriate objective for the supplier would be to maximize $\mathrm{SP}_{1}$ subject to the constraint that the buyer's expected profit is greater than or equal to $B_{2}$. Naturally, the equilibrium point should also satisfy the constraint $\mathrm{SP}_{1}>0$; otherwise, the supplier will not enter the contract.

Note that when there is an infinite supply in the spot market, the long-term supplier is forced to offer a price lower than the market, and thus the buyer's expected profit is always higher than in the case of single sourcing from the spot market [2].

The supplier needs to solve two different subproblems. First, the buyer's expected profit and optimal base stock policy with random deliveries from a single supplier are computed. Then, the supplier maximizes (12) in light of these values.

\subsection{The model with all-or-none spot supply availability}

A research stream in the literature has incorporated supply uncertainty into the periodic review inventory control framework by assuming a Bernoulli process for supplier availability in each period. An order that is placed with the supplier is fully received with probability $u$, and with probability $1-u$, the supplier cannot deliver any amount. Previous works that consider this sort of "all-or-none" supply availability include $[10,15,16]$. If we assume a similar form of uncertainty for the spot market supply in our model, it 
can be shown that the optimal inventory control policy for the buyer will still be the two-number policy described in Proposition 5.

Consider first the single-period problem. Analogous to (1), the buyer's expected profit function is

$$
S(I, Z)= \begin{cases}E L(Z) & \text { if } Z<I+R \\ u\left[E L(Z)-c_{2}(Z-I-R)\right]+(1-u) E L(I+R) & \text { if } Z \geqslant I+R,\end{cases}
$$

where $Z$ is the planned stocking level. For $Z \geqslant I+R$, with probability $u$, the buyer starts the period with $Z$ units on hand. With probability $1-u$, there is no item available in the spot market to satisfy the order, and $I+R$ is the actual stocking level realized. The derivative of $S(I, Z)$ with respect to $Z$ is

$$
S^{\prime}(I, Z)= \begin{cases}(p+\pi)(1-F(Z))-h F(Z) & \text { if } Z<I+R \\ u\left[(p+\pi)(1-F(Z))-h F(Z)-c_{2}\right] & \text { if } Z \geqslant I+R .\end{cases}
$$

Following steps similar to that in Proposition 1, we conclude that the two-number policy maximizes the buyer's expected profit in the single-period problem with all-or-none spot supply availability.

The recurrence relation in the multi-period problem is written as

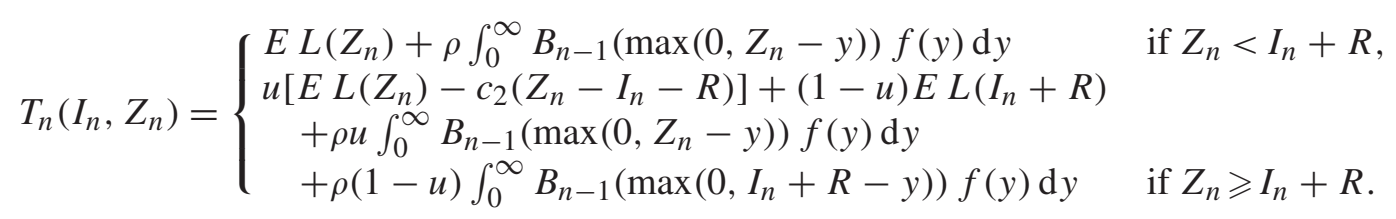

Differentiation of (14) with respect to $Z_{n}$ yields

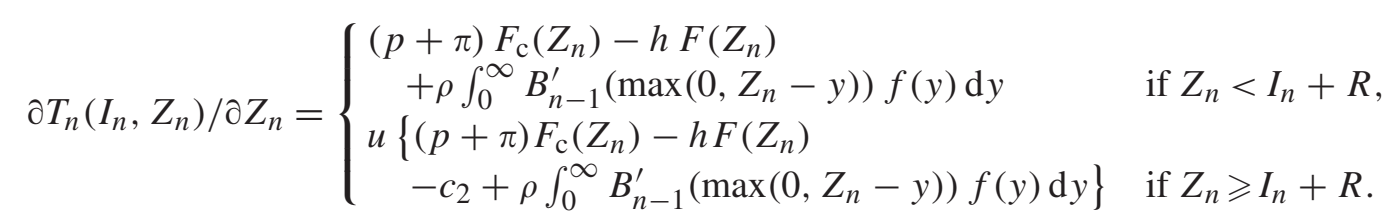

Then, analogous to Proposition 4, it can be shown that a two-number policy will be optimal for the finite horizon problem. Thus, in our capacity reservation model, the structure of the buyer's optimal inventory control policy is the same regardless of how the spot market supply uncertainty is modeled: as a quantity randomly drawn from a probability distribution, or as a Bernoulli process with a success probability $u$ of obtaining any desired amount from the spot market.

\section{Single-sourcing contract}

In this section, as a benchmark for comparison, we consider an alternative agreement with the buyer in which the long-term supplier is the sole supplier, and she agrees to have sufficient capacity available in each period against the maximum possible order amount that can be asked by the buyer in any period. We analyze the decisions of the parties under this alternative contract.

It is well known that, when the buyer acts as a newsvendor, the joint profit of the buyer and the supplier in a supply chain is maximized if the decisions of the parties are coordinated. When the deliveries by the supplier are linearly priced, the buyer's optimal stocking decision will be different from the optimal stocking level that maximizes the joint total profit of the buyer and the supplier. The inefficiencies caused 
by linear pricing can be avoided, and the maximum possible total system profit can be obtained by implementing a supply-chain-coordinating contract such as a quantity discount scheme or a two-part tariff (fixed fee plus per unit price). The total profit in a coordinated channel may be divided between the buyer and the supplier in different ways. When it is difficult to coordinate the channel for any reason, and non-linear pricing is not a practical alternative, we need to consider non-coordinated actions of the agents. In this section, we focus on the case where the supplier, knowing the buyer's reaction to her pricing decision, chooses the optimal (linear) supply price maximizing her expected profit as a Stackelberg leader. We consider two alternative single-source contracts between the buyer and the supplier: a per-unit price contract (UP), and a pure capacity reservation contract (pure CR). The contract with a fixed payment $c R$ per period for the reserved capacity $R$ is referred to as a pure CR contract since it is assumed that there is no spot market source available for the buyer.

The supplier's problem in Case 1 (UP contract) is

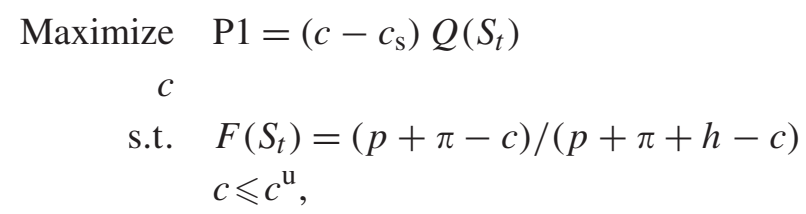

where $Q(r)=\int_{0}^{r} y f(y) \mathrm{d} y+r \int_{r}^{\infty} f(y) \mathrm{d} y$, the expected amount per period delivered to the buyer when the buyer follows a base stock policy with the base stock level $r$, and $c$ is the unit price charged by the supplier. Recall that $c_{\mathrm{S}}$ is the unit cost of production for the supplier. In the UP contract, the buyer pays $c$ for each unit delivered. The dependence of $Q\left(S_{t}\right)$ on $c$ is described by the well-known newsvendor critical fractile expression in the above formulation, with $F($.$) denoting the cdf of the demand for the$ product and $S_{t}$ the optimal base stock level associated with unit supply price $c$ (the buyer's expected profit per period $\left.=E L\left(S_{t}\right)-c Q\left(S_{t}\right)\right)$. There exists an upper bound on $c, c^{\mathrm{u}}>c_{2}$ such that when $c<c^{\mathrm{u}}$ the buyer contracts with the long-term supplier rather than buying from the uncertain spot market at $c_{2}$. When $c>c^{\mathrm{u}}$ the spot market becomes cheaper, and a long-term contract is less attractive to the buyer. We now show that the single-source supplier's objective function is concave in $c$ under a unit price contract when the demand distribution belongs to the increasing failure rate (IFR) class, which encompasses a large variety of commonly used probability distributions including normal distribution.

Proposition 6. In the single-sourcing case with UP contract, the supplier's expected profit function is concave in the supply price if the demand distribution is IFR.

Proof. It can be shown that

$$
\partial Q\left(S_{t}\right) / \partial S_{t}=F_{\mathrm{c}}\left(S_{t}\right)
$$

and $\partial S_{t} / \partial c=-h /\left[f\left(S_{t}\right)(p+\pi+h-c)^{2}\right]$. The IFR property implies that the failure rate, $r(y)$ is an increasing function of $y$ :

$$
r(y)=f(y) /(1-F(y)) .
$$




\section{Single source supplier's expected profit with UP and pure CR contracts}

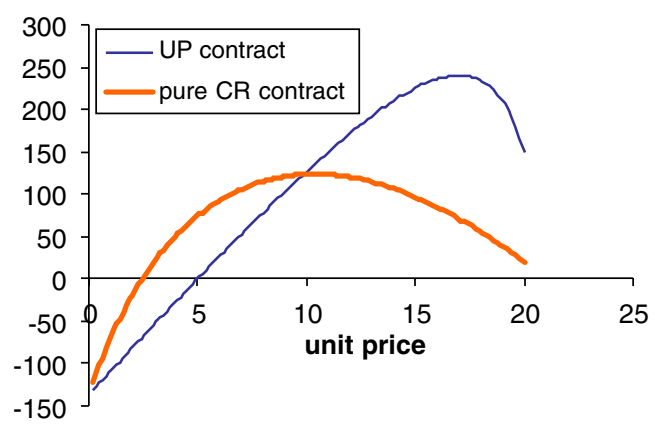

Fig. 3. Single-source supplier's expected profit as a function of the unit price $c$ (=per unit price in the UP contract, and unit capacity price in the pure $\mathrm{CR}$ contract).

Taking the derivative of $r(y)$ and rearranging the terms, we can state the IFR condition as

$$
K \equiv-(\mathrm{d} f(y) / \mathrm{d} y)(1-F(y)) /[f(y)]^{2}<1 .
$$

Routine algebra yields:

$$
\begin{aligned}
& \mathrm{dP} 1 / \mathrm{d} c=Q\left(S_{t}\right)-\left\{h^{2}\left(c-c_{\mathrm{s}}\right) /\left[f\left(S_{t}\right)(p+\pi+h-c)\right]\right\}, \\
& \mathrm{d}^{2} \mathrm{P} 1 / \mathrm{d} c^{2}=\left\{h^{2} /\left[f\left(S_{t}\right)(p+\pi+h-c)^{3}\right]\right\}\left\{-2+\left[\left(c-c_{\mathrm{s}}\right)(K-3) /(p+\pi+h-c)\right]\right\}<0,
\end{aligned}
$$

where $S_{t}$ is substituted for $y$ in the expression for $K$.

When the single-source supplier has a concave profit function, the optimal unit price, $w$, will occur either inside the feasible region ( $w<c^{\mathrm{u}}$ in this case), or the constraint will be binding, i.e., $w=c^{\mathrm{u}}$.

In Case 2 (pure CR contract), the supplier's problem is expressed as

$$
\begin{aligned}
\operatorname{Maximize} & \mathrm{P} 2=c R-c_{\mathrm{S}} Q(R) \\
c & \\
\text { s.t. } & F(R)=(p+\pi-c) /(p+\pi+h) .
\end{aligned}
$$

In this case, the buyer's optimal policy is also a base stock policy with base stock level $R$ (obtained by maximizing the buyer's expected profit per period $=E L(R)-c R$ ). There is also an upper bound on $c$, above which the spot market is the preferable source. It has been shown that, if the demand distribution is IFR, the supplier's expected profit function is concave in $c$ under a pure CR contract [2, Proposition 2].

For a specific example, the values of P1 and P2, expected profits associated with the UP contract and the pure CR contract, respectively, are plotted together in Fig. 3 (for $c_{\mathrm{s}}=5$ ). As illustrated in Fig. 3, the UP contract yields a higher maximum expected profit for the single-source supplier compared to the pure CR contract. The behavior of P1 and P2 plotted in Fig. 3 is typical; in general, for small values of $c$, the pure CR contract yields higher expected profits. As $c$ increases, the UP contract dominates the pure CR contract, and eventually the maximum expected profit of the supplier given the UP contract exceeds that given the pure CR contract. This implies that, if there is no restriction on the value of $c$ that can be selected, the single-source supplier chooses a per-unit price contract over a pure capacity reservation contract. 
We note that single sourcing under UP contract with a price higher than the spot market price may be difficult to enforce since the buyer has a motivation to use the lower cost spot market source whenever possible. Therefore, a control mechanism like vendor-managed inventory (VMI) may be needed. If there is no such mechanism, the supplier may be compelled to set its supply price equal to $c_{2}$, the prevailing spot market price, resulting in lower expected profits.

\section{Computational study}

To illustrate the concepts discussed in the earlier sections, we present some numerical examples. To compare the results in this paper with results in the problem with infinite spot market supply, we take the set of examples in [2] as the starting reference point. In particular, we use the following parameters: $\mu=30, h=2, \pi=6, c_{2}=10, p=15$ or $20, c_{\mathrm{S}}=5$. The demand for the product is distributed as Weibull with the shape parameter $\alpha$ being equal to 1,2 , or 3 . The probability density function for the Weibull distribution is $f(y)=\alpha \beta^{-\alpha} y^{\alpha-1} \exp \left(-(y / \beta)^{\alpha}\right), \alpha$ and $\beta>0$. When the mean of the Weibull distribution is fixed, a higher value of $\alpha$ implies a decrease in the variance of the distribution, and $\alpha=1$ corresponds to the exponential distribution. Similarly, the total random amount available in the spot market each period from suppliers other than the long-term supplier is assumed to be distributed as Weibull with mean $\gamma \in\{30,70\}$ and the shape parameter $\alpha_{\mathrm{s}}=2$.

Let $Q_{1}$ be the average amount per period ordered from the long-term supplier. According to our numerical results, there are a number of capacity price-capacity quantity combinations that leave the buyer with the expected profit of $B_{2}$, and give a profit to the long-term supplier that is very close to her maximum expected profit. In other words, the supplier may choose any alternative from a set of price-quantity pairs, and still remain in the vicinity of her maximum expected profit. By also taking into account the possible small errors in the results due to the discretization of continuous intervals, for each experimental point, we identified an appropriate capacity price-quantity pair which leads to an expected profit $\mathrm{SP}_{1}$ within $1 \%$ of the maximum profit observed. Let $S$ denote the buyer's optimal base stock level when only a spot market source is used, and BP the buyer's expected profit per period when the longterm supplier charges the selected unit capacity price, $c^{*}$. Also, let $T$ be the combined profit of the buyer and the long-term supplier. The results for the capacity reservation contract when $\gamma=30$ are shown in Table 1.

Table 2 displays the optimal solution for the single-source supplier in our numerical study. Given the data for the problem parameters, a UP contract is preferred over a pure CR contract by a single-source supplier. The single-source supplier also has to provide the buyer with the expected profit of $B_{2}$. The Weibull distribution used in our study is IFR when $\alpha \geqslant 1$. In our examples, we observe that the optimal unit price for the single-source supplier was always equal to $c^{\mathrm{u}}$. We note that it is possible that the optimal unit price could have fallen inside the feasible region if a different data set were used. We use $B_{1}$ to represent the buyer's expected profit in the single-sourcing relationship in Table 2. $S_{t}$ represents the optimal base stock level selected by the buyer corresponding to the given unit supply price, $w$.

\subsection{Impact of the capacity reservation contract on the supplier}

Although the supplier's expected profits are almost the same in both cases, a major disadvantage of the single-sourcing agreement compared to capacity reservation is the considerable level of decrease in the 
Table 1

Expected equilibrium price of capacity, $c^{*}$

\begin{tabular}{|c|c|c|c|c|c|c|c|c|c|c|}
\hline$\alpha$ & $c^{*}$ & $R$ & $\mathrm{SL}$ & SU & $S$ & $Q_{1}$ & $B_{2}$ & $\mathrm{BP}$ & $\mathrm{SP}_{1}$ & $T$ \\
\hline \multicolumn{11}{|c|}{ Case $1-p=20, c_{2}=10, c_{\mathrm{S}}=5, h=2, \pi=6, \gamma=30, \alpha_{\mathrm{s}}=2$} \\
\hline 1 & 4.9 & 62 & 62 & 80 & 82 & 27.74 & 136.12 & 136.74 & 165.08 & 301.83 \\
\hline 2 & 7.4 & 45 & 45 & 56 & 69 & 29.28 & 196.58 & 197.50 & 186.62 & 384.12 \\
\hline 3 & 9.0 & 38 & 38 & 47 & 63 & 29.50 & 213.19 & 213.01 & 194.52 & 407.53 \\
\hline \multicolumn{11}{|c|}{ Case $2-p=15, c_{2}=10, c_{\mathrm{S}}=5, h=2, \pi=6, \gamma=30, \alpha_{\mathrm{s}}=2$} \\
\hline 1 & 5.4 & 52 & 52 & 74 & 65 & 27.08 & 18.62 & 20.25 & 145.41 & 165.66 \\
\hline 2 & 7.2 & 44 & 44 & 53 & 58 & 29.03 & 67.27 & 67.53 & 171.65 & 239.18 \\
\hline 3 & 8.8 & 37 & 37 & 46 & 54 & 29.36 & 81.07 & 81.27 & 178.81 & 260.08 \\
\hline
\end{tabular}

Table 2

Expected equilibrium unit price, $w$, in the single-sourcing relationship

\begin{tabular}{|c|c|c|c|c|c|c|c|}
\hline$\gamma$ & $\alpha$ & $w$ & $S_{t}$ & $Q_{1}$ & $B_{1}$ & $\mathrm{SP}_{1}$ & $T$ \\
\hline \multicolumn{8}{|c|}{ Case $1-p=20, c_{2}=10, c_{\mathrm{s}}=5, h=2, \pi=6, \alpha_{\mathrm{s}}=2$} \\
\hline \multirow[t]{3}{*}{30} & 1 & 11.2 & 63 & 26.33 & 136.28 & 163.22 & 299.50 \\
\hline & 2 & 11.5 & 49 & 28.78 & 196.88 & 187.07 & 383.95 \\
\hline & 3 & 11.6 & 43 & 29.32 & 214.91 & 193.54 & 408.45 \\
\hline \multirow[t]{3}{*}{70} & 1 & 10.1 & 65 & 26.56 & 165.48 & 135.47 & 300.95 \\
\hline & 2 & 10.2 & 50 & 28.90 & 234.39 & 150.27 & 384.66 \\
\hline & 3 & 10.2 & 43 & 29.32 & 255.96 & 152.48 & 408.45 \\
\hline \multicolumn{8}{|c|}{ Case $2-p=15, c_{2}=10, c_{\mathrm{s}}=5, h=2, \pi=6, \alpha_{\mathrm{s}}=2$} \\
\hline \multirow[t]{3}{*}{30} & 1 & 10.7 & 54 & 25.04 & 20.00 & 142.73 & 162.73 \\
\hline & 2 & 11.0 & 45 & 28.20 & 68.36 & 169.18 & 237.54 \\
\hline & 3 & 11.1 & 40 & 28.87 & 83.51 & 176.08 & 259.59 \\
\hline \multirow[t]{3}{*}{70} & 1 & 10.1 & 55 & 25.20 & 35.13 & 128.54 & 163.66 \\
\hline & 2 & 10.1 & 46 & 28.36 & 93.86 & 144.64 & 238.50 \\
\hline & 3 & 10.1 & 41 & 29.04 & 112.61 & 148.10 & 260.71 \\
\hline
\end{tabular}

supplier's capacity utilization. In Table 3, we compare the supplier's capacity utilization rates under these two different agreements with the buyer. The capacity utilization rate is found by computing the ratio of the average delivery amount per period over the committed capacity per period. We use the buyer's optimal stocking level $S_{t}$ as the capacity committed per period from the single-source supplier in our calculations. Capacity committed per period is $R$ in the CR contract. The average delivery amounts per period, $Q_{1}$, in the single-sourcing and CR contracts are shown in Tables 1,2 , and 4 . $\mathrm{CU}_{\mathrm{CR}}=Q_{1} / R$ and $\mathrm{CU}_{\mathrm{SS}}=Q_{1} / S_{t}$ represent the average capacity utilizations under the capacity reservation and singlesourcing agreements, respectively. Of course, these calculations do not take into account the possible allocation by the supplier of her idle capacity to the needs of other customers. It is observed that when the buyer has access to the spot market source, the supplier may prefer the capacity reservation contract to the per-unit price contract not mainly because of higher expected profits, but because of the reduced probability 
Table 3

Average capacity utilization and profit per capacity rates for the long-term supplier

\begin{tabular}{|c|c|c|c|c|c|}
\hline$\gamma$ & $\alpha$ & $\mathrm{CU}_{\mathrm{CR}}$ & $\mathrm{CU}_{\mathrm{SS}}$ & $\mathrm{PPC}_{\mathrm{CR}}$ & $\mathrm{PPC}_{\mathrm{SS}}$ \\
\hline \multicolumn{6}{|c|}{ Case $1-p=20, c_{2}=10, c_{\mathrm{s}}=5, h=2, \pi=6, \alpha_{\mathrm{s}}=2$} \\
\hline \multirow[t]{3}{*}{30} & 1 & 44.7 & 41.8 & 2.66 & 2.59 \\
\hline & 2 & 65.1 & 58.7 & 4.15 & 3.82 \\
\hline & 3 & 77.6 & 68.2 & 5.12 & 4.50 \\
\hline \multirow[t]{3}{*}{70} & 1 & 46.2 & 40.9 & 2.29 & 2.08 \\
\hline & 2 & 65.1 & 57.8 & 3.35 & 3.00 \\
\hline & 3 & 77.6 & 68.2 & 4.02 & 3.55 \\
\hline \multicolumn{6}{|c|}{ Case $2-p=15, c_{2}=10, c_{\mathrm{s}}=5, h=2, \pi=6, \alpha_{\mathrm{s}}=2$} \\
\hline \multirow[t]{3}{*}{30} & 1 & 52.1 & 46.4 & 2.80 & 2.64 \\
\hline & 2 & 66.0 & 62.7 & 3.90 & 3.76 \\
\hline & 3 & 79.4 & 72.2 & 4.83 & 4.40 \\
\hline \multirow[t]{3}{*}{70} & 1 & 47.0 & 45.8 & 2.25 & 2.34 \\
\hline & 2 & 64.6 & 61.7 & 3.27 & 3.14 \\
\hline & 3 & 71.9 & 70.8 & 3.71 & 3.61 \\
\hline
\end{tabular}

Table 4

Expected equilibrium price of capacity, $c^{*}$

\begin{tabular}{|c|c|c|c|c|c|c|c|c|c|c|}
\hline$\alpha$ & $c^{*}$ & $R$ & SL & SU & $S$ & $Q_{1}$ & $B_{2}$ & $\mathrm{BP}$ & $\mathrm{SP}_{1}$ & $T$ \\
\hline \multicolumn{11}{|c|}{ Case $1-p=20, c_{2}=10, c_{\mathrm{s}}=5, h=2, \pi=6, \gamma=70, \alpha_{\mathrm{s}}=2$} \\
\hline 1 & 4.6 & 60 & 60 & 80 & 69 & 27.71 & 163.52 & 164.19 & 137.46 & 301.65 \\
\hline 2 & 6.6 & 45 & 45 & 56 & 53 & 29.28 & 233.70 & 233.50 & 150.62 & 384.12 \\
\hline 3 & 7.9 & 38 & 38 & 47 & 46 & 29.50 & 254.01 & 254.81 & 152.72 & 407.53 \\
\hline \multicolumn{11}{|c|}{ Case $2-p=15, c_{2}=10, c_{\mathrm{s}}=5, h=2, \pi=6, \gamma=70, \alpha_{\mathrm{s}}=2$} \\
\hline 1 & 4.6 & 58 & 58 & 74 & 58 & 27.24 & 35.03 & 35.63 & 130.60 & 166.23 \\
\hline 2 & 6.5 & 45 & 45 & 53 & 48 & 29.06 & 92.17 & 92.15 & 147.19 & 239.34 \\
\hline 3 & 7.3 & 41 & 41 & 45 & 43 & 29.47 & 109.85 & 109.61 & 151.94 & 261.55 \\
\hline
\end{tabular}

of experiencing costly idle capacity. When demand for the finished good is uncertain, manufacturers prefer their suppliers to maintain a high level of capacity to satisfy surges in demand; however, suppliers try to avoid overinvestment and the costs of idle capacity. Thus, the capacity reservation contract is a costreducing arrangement from the supplier perspective.

As a measure of profitability relative to capacity, we can use the ratio of the expected profit of the supplier per unit of capacity set aside for the buyer. Let $\mathrm{PPC}_{\mathrm{CR}}=\mathrm{SP}_{1} / R$ and $\mathrm{PPC}_{\mathrm{SS}}=\mathrm{SP}_{1} / S_{t}$ denote the values of this measure in the capacity reservation and single-sourcing agreements, respectively. The results in Table 3 illustrate the generally superior performance of the CR contract based on this measure.

\subsection{Impact of supply uncertainty}

Although the buyer is free to use the spot market, the average quantity purchased from the spot market is zero at the equilibrium in all of our examples in Tables 1 and 4. Thus, the long-term supplier chooses 
her price-quantity offer such that the buyer does not use the spot market source (or more precisely, uses it very little); effectively a single-sourcing relationship results. This is quite different from the infinite spot supply case in which the spot market is a second and active source of supply for the buyer in the resulting equilibrium. In our model, the primary value of the long-term supplier to the buyer is the delivery guarantee, not the savings in purchasing cost. The spot market cannot compete with the longterm supplier in this dimension. We note that these conclusions are based on the assumption that the long-term supplier is not restricted by an upper limit on her installed capacity. Buyers with regular and high-volume purchasing needs are less likely to use spot markets when there is a high chance of supply unavailability from short-term sellers. These buyers can be expected to use spot markets only when their preferred suppliers have constrained capacity. For example, the automobile industry, which uses several non-standardized and model-specific components cannot easily meet its procurement needs primarily from spot markets.

It can be thought that for sufficiently low spot prices, the spot market can capture a higher share of the buyer's business. Since the supplier has to provide the buyer with a higher profit in this case, it may be difficult for her to identify a feasible price that drives the amount purchased from the spot market to zero. In fact, there may not exist a feasible price that gives the long-term supplier a positive profit while giving the buyer the same amount of profit that he earns when he uses only the spot market source; in this situation the supplier will not offer a CR contract. On the other hand, in our numerical study we have observed that when the supplier can achieve a positive profit given the buyer's minimum required profit, the supplier's profit is always maximized when the spot market share is zero. As an example, for $c_{2}=4.5$ and $\gamma=30$, the average quantity per period purchased from the spot market in the equilibrium is still zero. We have not observed a case where the spot market constitutes a more significant portion of the buyer's total procurement amount, and at the same time the long-term supplier makes a positive profit in the equilibrium. Whether this outcome is possible under some other set of parameters and probability distributions may be a subject for further research. We expect that even with such changes in the input data, the long-term supplier will capture an increased share of the buyer's total order when going from the infinite spot supply to the risky spot supply case.

The reduction in sales to the buyer by spot market sources in conditions of uncertain supply is to some extent expected. Purchases from the spot source will be high in a period only when the demand for the finished good in the previous period and available spot supply in the current period are simultaneously high. The occurrence of this combination will be low when the average spot supply is similar to the average finished good demand, as is the case in Table 1.

The numerical results also indicate that the portion of goods obtained through advance purchase of capacity increases when we go from infinite supply to uncertain supply settings. For ease of reference, the portions of Table 4 in [2], which contain the numerical results for the infinite spot supply case, have been replicated in Table 5. For example, referring to Tables 5 and 1 , for $p=20, \alpha=2$, and $\gamma=30$, the reserved capacities per period are 19 and 45 in the infinite and uncertain supply cases, respectively. This impact of supply restrictions on advance purchase quantities has been previously pointed out in the literature based on single-period models [33]. On the other hand, under conditions of uncertain spot supply, as the average amount available in the spot market increases, the reserved capacity from the long-term supplier may increase. The increase in the average amount available in the spot market increases the minimum profit to be left to the buyer by the long-term supplier. This may lead to an increase in reserved capacity since the supplier can increase the buyer's profit either by reducing her capacity price, or by reducing the lost sales via higher reserved capacity and hence satisfying a larger portion of the demand. The results in 
Table 5

Expected equilibrium price of capacity, $c^{*}$ in the infinite spot supply case

\begin{tabular}{|c|c|c|c|c|c|c|}
\hline$\alpha$ & $c^{*}$ & $R$ & SL & $\mathrm{SU}$ & $\mathrm{BP}$ & $\mathrm{SP}_{1}$ \\
\hline \multicolumn{7}{|c|}{ Case $1-p=20, c_{2}=10, c_{\mathrm{s}}=5, h=2, \pi=6$} \\
\hline 1 & 9.1 & 15 & 60 & 137 & 178.4 & 61.5 \\
\hline 2 & 9.3 & 19 & 48 & 99 & 251.0 & 81.7 \\
\hline 3 & 9.2 & 22 & 42 & 76 & 276.9 & 92.4 \\
\hline \multicolumn{7}{|c|}{ Case $2-p=15, c_{2}=10, c_{\mathrm{s}}=5, h=2, \pi=6$} \\
\hline 1 & 9.1 & 15 & 50 & 127 & 47.9 & 61.5 \\
\hline 2 & 9.1 & 20 & 44 & 98 & 111.5 & 82.0 \\
\hline 3 & 9.5 & 21 & 40 & 89 & 124.3 & 94.5 \\
\hline
\end{tabular}

Tables 1 and 4 display both of these effects on the price and amount of reserved capacity. Interestingly, while higher spot availability but still uncertain supply may increase the amount of reserved capacity, moving to the infinite spot supply case (which may be viewed as an extreme case where the mean spot supply is infinitely high) will sharply reduce the reserved capacity since now the buyer has more power to dictate the resulting equilibrium point in the negotiations with the long-term supplier.

\subsection{Supply uncertainty vs. demand uncertainty}

According to our study, a long-term relationship between a buyer and a supplier is more likely when spot supply is uncertain rather than certain. This effect is contrary to the effect of variability in the demand for the buyer's finished product given infinite spot supply. As the demand for the finished good becomes more variable, the desirability of long-term contracts for the buyer decreases as long as the supply from spot market is guaranteed [2]. However, when the supply in the spot market is uncertain and the supplier is the leader setting the capacity price, our computational results suggest that the level of variability in the demand distribution is likely to have a lower impact on the buyer's long-term contract decisions. Under spot supply uncertainty, the long-term supplier, by offering a suitable capacity price, can induce the buyer to allocate a negligible part of his business to the spot market. As reflected in Tables 1 and 4, the changes in the finished good demand distribution do not appear to influence this ability of the supplier. In the infinite spot supply case, the cost of unutilized reserved capacity is an important factor for the buyer in his capacity reservation decision, and increasing demand variability here results in a choice to lower reserved capacity. In the uncertain spot supply case, the cost of unsatisfied demand for the finished good becomes more important, and the supplier uses this concern of the buyer to offer an attractive CR contract. The supplier now is not pressured to improve the buyer's profit as in the infinite spot supply case, and it is easier for the supplier to determine a suitable capacity price compared to the infinite spot supply case.

Note also that variability in demand for the finished good may have a different impact on the amount of capacity reserved, depending on whether spot supply is certain or uncertain. Tables 1 and 4 show that $R$ decreases as $\alpha$ increases (which corresponds to a lower demand variability), whereas in Table 5 (certain spot supply case) $R$ increases as $\alpha$ increases. 


\subsection{Optimal capacity price}

When the optimal capacity price of the supplier in our study is compared to that in the infinite supply case, we observe that the price is lower when there is uncertainty in the spot market. For example, for $p=20, \alpha=1$, and $\gamma=30$, the optimal capacity prices are 4.9 (from Table 1) and 9.1 (from Table 5) in the uncertain and infinite supply cases, respectively. In the infinite supply case, the motivating factor for the buyer in reserving capacity is the reduction in the purchase cost; the negotiation-based equilibrium unit capacity price leads to an increase in the buyer's profits compared to his profits in the case of single sourcing from the spot market (when it is assumed that the supplier has no power to make the buyer forego this extra profit potential). As noted previously when the spot supply is uncertain, the equilibrium capacity price is harder to define. The buyer's primary motivating factor in reserving capacity in this case is the guaranteed delivery. When we allow the buyer the same amount of profits in both the CR contract and the single sourcing from the spot market case, the optimal capacity price for the long-term supplier is observed to be lower than in the infinite supply case. Thus, interestingly, in uncertain spot markets, suppliers selling capacity in advance may charge less than the spot market price, and emphasize volume increase rather than charging a premium over the spot market price; this will maximize their expected profits. Although this result may be predictable in the case of infinite supply spot markets, it is not an intuitively expected result in our model since the alternative of higher-than-spot market price for advance purchases cannot be discarded at the outset when the spot market availability is uncertain. We also note that offering reduced prices to a regular, long-term customer is similar to the general revenue management practice of discounting early sales and charging late-arriving customers a premium [34].

Although we consider a limited set of combinations of model parameters in our computational study, similar conclusions can be expected to hold if the other widely known types of unimodal demand and supply probability distributions (e.g., normal) are used, and the cost data remain approximately in the same range.

\subsection{Dependence of the spot market price on the spot quantity available}

As noted previously, the spot market price may change depending on the quantity available in the spot market at any given time. In this section, we investigate the decisions of parties when there is a linear relationship between the spot price and quantity as follows:

$$
c_{x}=\max \{10+(30-x) / 15,4\},
$$

where $c_{x}$ is the spot price for the item, and $x$ is the total quantity available in the spot market. The average amount available in the spot market in a period is assumed as 30, and the spot price function in (15) is truncated from below at $c_{x}=4$.

We note that the spot market is the secondary source of supply for the buyer, and the impact of quantity-dependent spot price on the buyer's optimal inventory policy decreases as the capacity reserved from the long-term supplier, $R$, increases. Hence, the assumption of constant spot price instead of quantitydependent spot price is not as restrictive when $R$ is not very low. Even for low $R$ values, the impact of quantity-dependent spot price on the buyer's optimal policy may be negligible. To demonstrate this, we solved the single-period problem using simulation for both a constant spot price $\left(c_{2}=10\right)$ scenario and a quantity-dependent spot price $\left(c_{x}\right)$ scenario, keeping all other data fixed. Figs. 2 and 4 show the optimal 


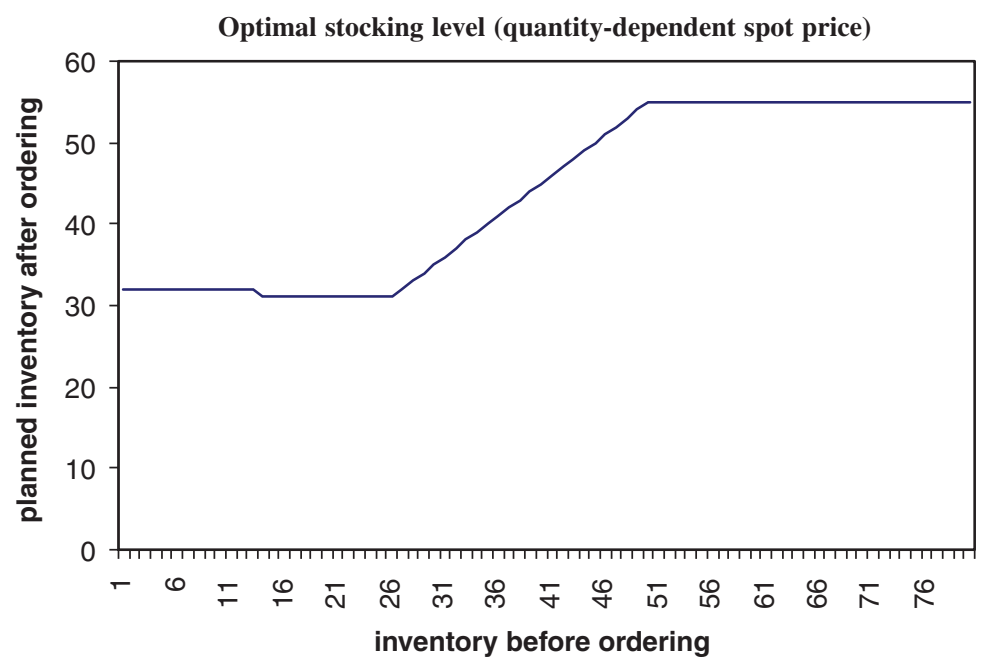

Fig. 4. Buyer's optimal inventory decision in the single-period problem under quantity-dependent spot price.

planned inventory after ordering as a function of the starting inventory in the constant spot price and quantity-dependent spot price cases, respectively. The results for the constant spot price case are consistent with the analytical values of $Z_{1}$ and $Z_{2}$ implied by Proposition 1 . In simulations, the following values were used: $R=5, p=20, \alpha=\alpha_{\mathrm{s}}=2$, and $\gamma=30$. As the comparison of Figs. 2 and 4 indicates, the optimal policies in the two cases are very similar. We observed a similar pattern in simulations (results not shown here) in which other combinations of these parameters were used. It can be argued that if the quantity-dependence of the spot price does not influence the buyer's decision significantly in the singleperiod case, an even smaller influence can be expected in the multi-period case because of the averaging effect.

Now turning our attention to the multi-period problem, we first consider the buyer's inventory policy when only the spot market source is present. The optimal (stationary) stocking quantity, denoted as $S_{\mathrm{s}}$, maximizing the buyer's expected profit per period when the spot price changes according to (15) is found using simulation; the values of $S_{\mathrm{s}}$ are listed in Table 7. The single-source supplier's optimal unit supply price, $w$, given the constraint on the buyer's profit is shown in Table 6 , analogous to Table 2 . Recall that the buyer's expected profit in single sourcing, $B_{1}$, has to be greater than or equal to the buyer's maximum expected profit when items are fully sourced from the spot market, $B_{2}$. Table 6 displays the expected CR contract parameters when the spot price is determined from (15); this differs from Table 1 where spot price is equal to a constant, $c_{2}$. Comparison of the results in Tables 6 and 7 indicates that the supplier's expected profit does not differ significantly in the single-sourcing and CR contract scenarios; this is similar to the constant spot price case examined in Section 5. Note that the results in Table 7 are based on the buyer following a two-number inventory control policy, as in the constant spot price case. Although the optimality of this policy is not guaranteed in the quantity-dependent spot price case, the similarity of supplier profits in Tables 6 and 7 suggests that the supplier's profit with a CR contract will tend to be close to her profit in the single-sourcing case, even if the buyer follows his (possibly different) true optimal control policy. The weighted-average spot price, $c_{\mathrm{wa}}$, in Table 7 represents the long-run average 
Table 6

Expected equilibrium unit price, $w$, in the single-sourcing relationship when the spot price is quantity-dependent

\begin{tabular}{cccccccc}
\hline$p$ & $\alpha$ & $S_{t}$ & $Q_{1}$ & $B_{1}$ & $\mathrm{SP}_{1}$ & $T$ \\
\hline 20 & 1 & 10.7 & 64 & 26.45 & 149.53 & 150.75 & 300.28 \\
& 2 & 11.1 & 49 & 28.78 & 208.39 & 175.56 & 483.95 \\
& 3 & 11.2 & 43 & 29.32 & 226.64 & 30.09 & 133.58 \\
15 & 1 & 10.3 & 55 & 25.20 & 79.64 & 157.90 & 163.66 \\
& 2 & 10.6 & 45 & 28.20 & 92.17 & 167.42 & 237.54 \\
& 10.8 & 40 & 28.87 & & & 259.59 \\
\hline
\end{tabular}

$\gamma=30, c_{\mathrm{S}}=5, h=2, \pi=6, \alpha_{\mathrm{S}}=2$.

Table 7

Expected equilibrium price of capacity, $c^{*}$ when the spot price is quantity-dependent

\begin{tabular}{|c|c|c|c|c|c|c|c|c|c|c|c|}
\hline$\alpha$ & $c^{*}$ & $R$ & SL & SU & $c_{\mathrm{wa}}$ & $S_{\mathrm{s}}$ & $Q_{1}$ & $B_{2}$ & $\mathrm{BP}$ & $\mathrm{SP}_{1}$ & $T$ \\
\hline \multicolumn{12}{|c|}{ Case $1-p=20, c_{\mathrm{s}}=5, h=2, \pi=6, \gamma=30, \alpha_{\mathrm{s}}=2$} \\
\hline 1 & 4.8 & 61 & 61 & 80 & 9.60 & 84 & 27.73 & 147.03 & 147.58 & 154.17 & 301.74 \\
\hline 2 & 7.0 & 46 & 46 & 55 & 9.59 & 71 & 29.24 & 207.51 & 208.84 & 175.82 & 384.65 \\
\hline 3 & 8.3 & 40 & 40 & 47 & 9.60 & 66 & 29.59 & 223.97 & 224.32 & 184.06 & 408.38 \\
\hline \multicolumn{12}{|c|}{ Case $2-p=15, c_{\mathrm{S}}=5, h=2, \pi=6, \gamma=30, \alpha_{\mathrm{s}}=2$} \\
\hline 1 & 4.8 & 57 & 57 & 74 & 9.62 & 68 & 27.22 & 28.34 & 28.66 & 137.51 & 166.17 \\
\hline 2 & 6.9 & 44 & 44 & 53 & 9.62 & 61 & 29.03 & 77.34 & 80.73 & 158.45 & 239.18 \\
\hline 3 & 8.3 & 38 & 38 & 46 & 9.62 & 57 & 29.42 & 91.05 & 92.26 & 168.28 & 260.54 \\
\hline
\end{tabular}

cost of a unit purchased from the spot market. It is computed via simulation, and is associated with the scenario where the buyer sources from the spot market only.

The distribution of total system profit among the parties in the CR contract is generally similar to that in the constant spot price case. Because the average spot price is approximately $\$ 9.6$ (as seen in Table 7), which is less than the constant price of $\$ 10$ in Section 5, the buyer's profit has increased while the supplier's profit has decreased. The range over which the supplier profits change as the demand variability (reflected by $\alpha$ ) changes is approximately the same in the quantity-dependent spot price case and the constant spot price case. For $p=20$, the difference between the highest and lowest supplier profits is $\$ 29.44$ (\$194.52-165.08) in Table 1, whereas the corresponding difference is $\$ 29.89(\$ 184.06-154.17)$ in Table 7. In summary, results from our implementation suggest that, under typical demand and supply distributions, solving the capacity reservation model based on a constant spot price yields a reasonably good approximate solution for the problem with a quantity-dependent spot price assumption.

\section{Conclusion}

In this paper, we have explored the effects of capacity reservation agreements on manufacturers and their preferred suppliers in a multi-period setting. Our numerical study indicates that the capacity reservation 
agreement gives the supplier the same level of profit as the traditional unit price contract, but it enables the supplier to achieve a higher capacity utilization. In some respects, the capacity reservation contract is easier to implement compared to the unit price contract. First, the capacity committed per period is lower, which means a lower capital investment, and less financial burden for the supplier. Reducing supplier capacity commitment via a CR contract has a similar effect to sharing information among parties in a supply chain so that unnecessary capacity is eliminated, and productivity and profitability increase [35]. Second, opportunistic behavior by the buyer is less likely since a capacity reservation contract does not have the problem of having to charge a higher-than-market price as in the unit price contract. Third, cash flows between the parties are smoother, more predictable, and easier to monitor.

There is an interesting result regarding the optimal capacity price decided by the supplier. The equilibrium unit capacity price is intuitively expected to be higher under the uncertain supply scenario compared to the infinite supply. But our numerical examples do not confirm this expectation. The supplier is estimated to have more power when she competes against an uncertain spot market. She can drive the spot market share in the buyer's business to zero by quoting an appropriate price-quantity pair in which the price may be lower than the optimal price under infinite supply conditions.

For a manufacturer, supply variability is likely to have a greater influence than demand variability in the selection of long- vs. short-term purchasing strategies. Only when there is an assured supply in the spot market will the variability of the demand for the manufactured good start exerting an important effect over the term of purchasing commitments.

Our framework can be enriched by taking into account some additional factors influencing procurement decisions. The modeling of negotiations between a manufacturer and a supplier subject to an independent spot market influence is a conceptually useful but nonetheless approximate representation of bargaining dynamics in real-world supply chains. More insights can be obtained by incorporating interactions among multiple buyers and suppliers in this basic framework.

\section{Acknowledgements}

The author thanks two anonymous reviewers for their helpful comments.

\section{Appendix A.}

Proof of Proposition 2. The proof is done inductively in two parts. First, we show the concavity of the expected profit in the last period of the planning horizon. Then, assuming concavity for the $N-1$-period problem, we show the concavity for the $N$-period problem. We first consider the last period, and show that the single-period profit function $B_{1}\left(I_{1}\right)=P\left(I_{1}\right)$ is concave.

For $Z_{1} \geqslant I_{1}+R$, the first and second partial derivatives of (1) are

$$
\begin{aligned}
\partial S\left(I_{1}, Z_{1}\right) / \partial I_{1}= & c_{2} G_{\mathrm{c}}\left(Z_{1}-I_{1}-R\right)+(p+\pi) G\left(Z_{1}-I_{1}-R\right) \\
& -(p+\pi+h) \int_{0}^{Z_{1}-I_{1}-R} F\left(I_{1}+R+x\right) g(x) \mathrm{d} x,
\end{aligned}
$$




$$
\begin{aligned}
\partial^{2} S\left(I_{1}, Z_{1}\right) / \partial I_{1}^{2}= & g\left(Z_{1}-I_{1}-R\right)\left[(p+\pi+h) F\left(Z_{1}\right)-\left(p+\pi-c_{2}\right)\right] \\
& -(p+\pi+h) \int_{0}^{Z_{1}-I_{1}-R} f\left(I_{1}+R+x\right) g(x) \mathrm{d} x .
\end{aligned}
$$

Let $Z_{1}^{*}$ be the value of $Z_{1}$ that satisfies the first-order condition for the period starting inventory level, i.e., $\partial S\left(I_{1}, Z_{1}\right) / \partial Z_{1}=0$ when $Z_{1}=Z_{1}^{*}$. The first term on the RHS of the second derivative expression is zero when we substitute $Z_{1}=Z_{1}^{*}$. Thus, $\partial^{2} S\left(I_{1}, Z_{1}\right) / \partial I_{1}^{2}<0$. Referring to Eq. (1), if $Z_{1}<I_{1}+R$, $S\left(I_{1}, Z_{1}\right)=E L\left(Z_{1}\right)$. Hence, $\partial S\left(I_{1}, Z_{1}\right) / \partial I_{1}=\partial^{2} S\left(I_{1}, Z_{1}\right) / \partial I_{1}^{2}=0$ for $Z_{1}<I_{1}+R$. Thus, $P\left(I_{1}\right)$ is concave. We can replace the subscript 1 by $n$ in the preceding analysis, and similar results hold for $S\left(I_{n}, Z_{n}\right)$ associated with any period $n$. Now we show that $B_{n}\left(I_{n}\right)$ is concave. Consider $Z_{n} \geqslant I_{n}+R$. From (5),

$$
\begin{aligned}
\partial T_{n}\left(I_{n}, Z_{n}\right) / \partial I_{n}= & \partial S\left(I_{n}, Z_{n}\right) / \partial I_{n} \\
& +\rho \int_{0}^{\infty} \int_{0}^{Z_{n}-I_{n}-R} B_{n-1}^{\prime}\left(\max \left(0, I_{n}+R+x-y\right)\right) g(x) f(y) \mathrm{d} x \mathrm{~d} y,
\end{aligned}
$$

and after using the first-order condition for $Z_{n}$,

$$
\begin{aligned}
\partial^{2} T_{n}\left(I_{n}, Z_{n}\right) / \partial I_{n}^{2}= & -(p+\pi+h) \int_{0}^{Z_{n}-I_{n}-R} f\left(I_{n}+R+x\right) g(x) \mathrm{d} x \\
& +\rho \int_{0}^{\infty} \int_{0}^{Z_{n}-I_{n}-R} B_{n-1}^{\prime \prime}\left(\max \left(0, I_{n}+R+x-y\right)\right) g(x) f(y) \mathrm{d} x \mathrm{~d} y .
\end{aligned}
$$

Using inductive argument, it follows that $\partial^{2} T_{n}\left(I_{n}, Z_{n}\right) / \partial I_{n}^{2}<0$. Using (4), we can similarly show that $\partial^{2} T_{n}\left(I_{n}, Z_{n}\right) / \partial I_{n}^{2}<0$ for $Z_{n}<I_{n}+R$; hence, $\partial^{2} B_{n}\left(I_{n}\right) / \partial I_{n}^{2}<0$.

Proof of Proposition 3. Consider the case $Z_{n} \geqslant I_{n}+R$. Using (10), $\partial^{2} T_{n}\left(I_{n}, Z_{n}\right) / \partial Z_{n}^{2} \leqslant 0$ if the following inequality holds:

$$
\begin{aligned}
G_{\mathrm{c}}\left(Z_{n}-I_{n}-R\right)\left\{f\left(Z_{n}\right)(p+\pi+h)-\rho \int_{0}^{\infty} B_{n-1}^{\prime \prime}\left(\max \left(0, Z_{n}-y\right)\right) f(y) \mathrm{d} y\right\} \\
\geqslant-g\left(Z_{n}-I_{n}-R\right)\left\{-c_{2}+(p+\pi) F_{\mathrm{c}}\left(Z_{n}\right)\right. \\
\left.\quad-h F\left(Z_{n}\right)+\rho \int_{0}^{\infty} B_{n-1}^{\prime}\left(\max \left(0, Z_{n}-y\right)\right) f(y) \mathrm{d} y\right\} .
\end{aligned}
$$

Let $Z_{n}^{*}$ be the value of $Z_{n}$ that sets Eq. (8) to zero. Consider the region $Z_{n} \leqslant Z_{n}^{*}$. The RHS of (A.1) is negative when the bracketed term in the RHS is non-negative, or equivalently, when it decreases in $Z_{n}$. But the bracketed term decreases in $Z_{n}$ since, from Proposition 2, $B_{n-1}^{\prime \prime}\left(\max \left(0, Z_{n}-y\right)\right)$ is negative. In the region $Z_{n}>Z_{n}^{*}, \partial T_{n}\left(I_{n}, Z_{n}\right) / \partial Z_{n}<0$ since $B_{n-1}^{\prime \prime}\left(\max \left(0, Z_{n}-y\right)\right)$ is negative. Thus, $T_{n}\left(I_{n}, Z_{n}\right)$ is quasi-concave in $Z_{n}$ for $Z_{n} \geqslant I_{n}+R$.

Now consider the case $Z_{n}<I_{n}+R$. From (9), $\partial^{2} T_{n}\left(I_{n}, Z_{n}\right) / \partial Z_{n}^{2} \leqslant 0$ if the following inequality holds:

$$
f\left(Z_{n}\right)(p+\pi+h) \geqslant \rho \int_{0}^{\infty} B_{n-1}^{\prime \prime}\left(\max \left(0, Z_{n}-y\right)\right) f(y) \mathrm{d} y .
$$


Again, from Proposition $2, B_{n-1}^{\prime \prime}\left(\max \left(0, Z_{n}-y\right)\right)$ is negative. Hence, $T_{n}\left(I_{n}, Z_{n}\right)$ is concave in $Z_{n}$ for $Z_{n}<I_{n}+R$.

Proof of Proposition 4. Let

$$
\begin{aligned}
& \mathrm{SL}_{n}\left(I_{n}\right)=\max \left\{Z_{n}:(p+\pi) F_{\mathrm{c}}\left(Z_{n}\right)-h F\left(Z_{n}\right)+\rho \int_{0}^{\infty} B_{n-1}^{\prime}\left(\max \left(0, Z_{n}-y\right)\right) f(y) \mathrm{d} y \geqslant c_{2}\right\}, \\
& \mathrm{SU}_{n}\left(I_{n}\right)=\max \left\{Z_{n}:(p+\pi) F_{\mathrm{c}}\left(Z_{n}\right)-h F\left(Z_{n}\right)+\rho \int_{0}^{\infty} B_{n-1}^{\prime}\left(\max \left(0, Z_{n}-y\right)\right) f(y) \mathrm{d} y \geqslant 0\right\} .
\end{aligned}
$$

Referring to (6), (8) and Proposition 3 imply that $\mathrm{SU}_{n}\left(I_{n}\right) \geqslant \mathrm{SL}_{n}\left(I_{n}\right)$. The remaining steps are similar to the single-period case (Proposition 1), and thus are omitted.

Proof of Proposition 5. Let $B(I)$ be the value function in the infinite horizon problem, i.e., the maximum total discounted profit when the starting inventory is $I$. Since the environment is stationary and the buyer faces the same problem in each period, the functional equation of dynamic programming is (cf. (4)-(5))

$$
\begin{aligned}
B(I)= & S(I, Z)+\rho \int_{0}^{\infty} B(\max (0, Z-y)) f(y) \mathrm{d} y, \quad \text { if } Z<I+R, \\
B(I)= & S(I, Z)+\rho \int_{0}^{\infty} \int_{0}^{Z-I-R} B(\max (0, I+R+x-y)) g(x) f(y) \mathrm{d} x \mathrm{~d} y \\
& +\rho(1-G(Z-I-R)) \int_{0}^{\infty} B(\max (0, Z-y)) f(y) \mathrm{d} y, \quad \text { if } Z \geqslant I+R .
\end{aligned}
$$

We use Theorem 8-14 of Heyman and Sobel [36] to prove that $B(I)=\lim _{n \rightarrow \infty} B_{n}(I)$ satisfies the functional equation of dynamic programming. To this end, we need to show that conditions a-d of Theorem 8-14 are satisfied in the current problem.

Let $T(I, Z)=\lim _{n \rightarrow \infty} T_{n}(I, Z)$. Condition c requires that $S(I, Z)$ must be bounded. We show that we can plausibly assume $S(I, Z)$ is bounded. Although $S(I, Z)$ is not bounded from below for $Z \geqslant I$, we can assume an upper bound on $Z$, say $Z^{\mathrm{u}}$, such that the maximum in (A.2) is attained in a compact set $Z \in\left[I, Z^{\mathrm{u}}\right]$. A similar approach is used in Proposition 6 of Wang and Gerchak [13]. The finite value $Z^{\mathrm{u}}$ is such that $S(I, Z)<0$ for all $Z>Z^{\mathrm{u}}$; the quasi-concavity of $S(I, Z)$ shown in Proposition 1 implies that there exists such $Z^{\mathrm{u}}$. On the other hand, Proposition 1 also implies that $S(I, Z) \leqslant M$ where $M$ is a finite upper bound on the single-period expected profit. Hence, $S(I, Z)$ is bounded for $Z \in\left[I, Z^{\mathrm{u}}\right]$. Using Proposition 8-4 of [36], for each $I$, there exists $B(I)=\lim _{n \rightarrow \infty} B_{n}(I)$; hence, condition a is satisfied. Condition b, $S(I, Z) \geqslant 0$, is satisfied for $Z \in\left[I, Z^{\mathrm{u}}\right] . S(I, Z)$ is continuous, and thus, condition d, the continuity of $T(I, Z)$ can be proved by induction.

$B(I)$ is concave in $I$ since $B_{n}(I)$ is concave from Proposition 2. It is also true that $B_{n}(I) \geqslant B_{n-1}(I)$. Similar to Proposition 3, we can show that $T(I, Z)$ is quasi-concave in $Z$. Then, it can be shown similar to Proposition 4 that a two-number policy is optimal for the infinite horizon; the use of this policy will yield the following actual starting inventory levels:

$$
Z_{\mathrm{nr}}= \begin{cases}I_{n}+R+\min \left(\mathrm{SL}-I_{n}-R, x_{n}\right) & \text { if } I_{n} \leqslant \mathrm{SL}-R \\ I_{n}+R & \text { if } \mathrm{SL}-R<I_{n}<\mathrm{SU}-R \\ \mathrm{SU} & \text { if } \mathrm{SU}-R<I_{n} .\end{cases}
$$


It remains to show the convergence of control policies. Lemma 8-5 of [36] implies

$$
B^{\prime}(I)=\lim _{n \rightarrow \infty} B_{n}^{\prime}(I),
$$

which, combined with (6) and (8), results in

$$
Z^{*}(I)=\lim _{n \rightarrow \infty} Z_{n}^{*}(I)
$$

Hence, the optimal policy of the multi-period problem converges to an optimal stationary policy for the infinite horizon problem (cf. [13, Proposition 8]).

\section{References}

[1] Pyke DF, Johnson ME. Sourcing strategy and supplier relationships: alliances vs. E-procurement. In: Harrison TP, Lee HL, Neale JJ, editors. The practice of supply chain management-where theory and application converge. Dordrecht: Kluwer Publishers; 2003.

[2] Serel DA, Dada M, Moskowitz H. Sourcing decisions with capacity reservation contracts. European Journal of Operational Research 2001;131:635-48.

[3] Kleindorfer PR, Wu DJ. Integrating long and short term contracting via business-to-business exchanges for capital intensive industries. Management Science 2003;49:1597-615.

[4] Henig M, Gerchak Y, Ernst R, Pyke DF. An inventory model embedded in designing a supply contract. Management Science 1997;43:184-9.

[5] Van Norden L, Van de Velde S. Multi-product lot-sizing with a transportation capacity reservation contract. European Journal of Operational Research 2005;165:127-38.

[6] Bonser JS, Wu SD. Procurement planning to maintain both short-term adaptiveness and long-term perspective. Management Science 2001;47:769-86.

[7] Wu DJ, Kleindorfer PR, Zhang JE. Optimal bidding and contracting strategies for capital-intensive goods. European Journal of Operational Research 2002;137:657-76.

[8] Spinler S, Huchzermeier A. The valuation of options on capacity with cost and demand uncertainty. European Journal of Operational Research 2006, forthcoming

[9] Seifert RW, Thonemann UW, Hausman WH. Optimal procurement strategies for online spot markets. European Journal of Operational Research 2004;152:781-99.

[10] Ciarallo FW, Akella R, Morton TE. A periodic review, production planning model with uncertain capacity and uncertain demand—optimality of extended myopic policies. Management Science 1994;40:320-32.

[11] Gullu R. Base stock policies for production/inventory problems with uncertain capacity levels. European Journal of Operational Research 1998;105:43-51.

[12] Iida T. A non-stationary periodic review production-inventory model with uncertain production capacity and uncertain demand. European Journal of Operational Research 2002;140:670-83.

[13] Wang Y, Gerchak Y. Periodic review production models with variable capacity, random yield, and uncertain demand. Management Science 1996;42:130-7.

[14] Hwang J, Singh MR. Optimal production policies for multi-stage systems with setup costs and uncertain capacities. Management Science 1998;44:1279-94.

[15] Parlar M, Wang Y, Gerchak Y. A periodic review inventory model with Markovian supply availability. International Journal of Production Economics 1995;42:131-6.

[16] Ozekici S, Parlar M. Inventory models with unreliable suppliers in random environment. Annals of Operations Research 1999;91:123-36.

[17] Tan B. Subcontracting with availability guarantees: production control and capacity decisions. IIE Transactions 2004;36:711-24.

[18] Mohebbi E. Supply interruptions in a lost-sales inventory system with random lead time. Computers \& Operations Research 2003;30:411-26. 
[19] Federgruen A, Zipkin P. An inventory model with limited production capacity and uncertain demands. I. The average-cost criterion. Mathematics of Operations Research 1986;11:193-207.

[20] Erkoc M, Wu SD. Managing high-tech capacity expansion via reservation contracts. Production and Operations Management 2005;14:232-51.

[21] Jin M, Wu SD. Modeling capacity reservation in high-tech manufacturing. Working paper, Lehigh University, Pennsylvania, 2001.

[22] Deng S, Yano CA. On the role of a second purchase opportunity in a two-echelon supply chain. Working paper, University of California, Berkeley, 2002.

[23] Cachon GP. The allocation of inventory risk in a supply chain: push, pull and advance-purchase discount contracts. Management Science 2004;50:222-38.

[24] Ferguson ME. When to commit in a serial supply chain with forecast updating. Naval Research Logistics 2003;50: 917-36.

[25] Ferguson ME, DeCroix GA, Zipkin PH. Commitment decisions with partial information updating. Naval Research Logistics 2005, forthcoming.

[26] Tsay AA. The quantity flexibility contract and supplier-customer incentives. Management Science 1999;45:1339-58.

[27] Burnetas A, Ritchken P. Option pricing with downward sloping demand curves: the case of supply chain options. Management Science 2005;51:566-80.

[28] Kamrad B, Siddique A. Supply contracts, profit sharing, switching, and reaction options. Management Science 2004;50: 64-82.

[29] Babich V. Vulnerable options in supply chains: effects of supplier competition. Working paper, University of Michigan, 2004.

[30] Taylor TA. Supply chain coordination under channel rebates with sales effort effects. Management Science 2002;48: 992-1007.

[31] Lee HL. Aligning supply chain strategies with product uncertainties. California Management Review 2002;44(3):105-19.

[32] Bazaraa MS, Sherali HD, Shetty CM. Nonlinear programming: theory and applications. 2nd ed., New York: Wiley; 1993.

[33] Xie J, Shugan SM. Electronic tickets, smart cards, and online prepayments: when and how to advance sell. Marketing Science 2001;20:219-43.

[34] Desiraju R, Shugan SM. Strategic service pricing and yield management. Journal of Marketing 1999;63:44-56.

[35] Schwarz LB. The state of practice in supply chain management: a research perspective. In: Geunes J, Akcali E, Pardalos PM, Romeijn HE, Shen ZJ, editors. Applications of supply chain management and E-commerce research. Berlin: Springer; 2005.

[36] Heyman DP, Sobel MJ. Stochastic models in operations research, vol. 2. New York: McGraw-Hill; 1984. 